\title{
Association of dietary inflammatory potential with cardiometabolic risk factors and diseases: a systematic review and dose- response meta-analysis of observational studies
}

Zahra Aslani ${ }^{1,2}$, Omid Sadeghi ${ }^{1,2}$, Motahar Heidari-Beni ${ }^{3}$, Hoda Zahedi ${ }^{4}$, Fereshteh Baygi ${ }^{5}$, Nitin Shivappa ${ }^{6,7,8}$, James R. Hébert ${ }^{6,7,8}$, Sajjad Moradi9,10, Gity Sotoudeh ${ }^{1}$, Hamid Asayesh ${ }^{11}$, Shirin Djalalinia12,13 and Mostafa Qorbani ${ }^{14,15^{*}}$

\begin{abstract}
Context: The association of dietary inflammatory index $\left(\mathrm{D} \|{ }^{\circledR}\right)$, as an index of inflammatory quality of diet, with cardiometabolic diseases (CMDs) and risk factors (CMRFs) has been inconsistent in previous studies.

Objective: The current systematic review and dose-response meta-analysis was performed to investigate the association of the DII score with CMDs and CMRFs.

Data Sources: All published observational studies (cohort, case-control and cross-sectional) using PubMed/Medline, Scopus, ISI Web of Science, and Google Scholar databases were retrieved from inception through November 2019.

Data extraction: Two reviewers independently extracted the data from included studies.

Data analysis: Pooled hazard ratio (HR) or odds ratio (OR) were calculated by using a random-effects model.

Results: Ten prospective cohort studies (total $n=291,968$ ) with 31,069 CMDs-specific mortality, six prospective cohort studies (total $n=43,340$ ) with 1311 CMDs-specific morbidity, two case-control studies with 2140 cases and 6246 controls and one cross-sectional study (total $n=15,613$ ) with 1734 CMDs-specific morbidity were identified for CMDs. Meta-analyses of published observational studies demonstrated that the highest DII score category versus the lowest DII score category was associated with 29\% increased risk of CMDs mortality (HR $=1.29 ; 95 \%$ confidence interval (CI) 1.18, 1.41). Moreover, there was a significant association between the DII score and risk of CMDs in cohort studies ( $H R=1.35 ; 95 \% \mathrm{Cl} 1.13,1.61)$ and non-cohort study $(H R=1.36 ; 95 \% \mathrm{Cl} 1.18,1.57)$. We found a significant association between the DII score and metabolic syndrome (MetS) (OR: 1.13; 95\% Cl 1.03, 1.25), hyperglycemia and hypertension. None-linear dose response meta-analysis showed that there was a significant association between the DIl score and risk of CMDs mortality $\left(P_{\text {nonlinearity }}<0.001\right)$. Moreover, evidence of none-linear association between the DIl score and risk of CMDs was not observed ( $p$-value $=0.1$ ).
\end{abstract}

Conclusions: Adherence to pro-inflammatory diet was associated with increased risk of CMDs, mortality and MetS. Keywords: Diet, Inflammation, Cardiovascular diseases, Dietary inflammatory index

*Correspondence: mqorbani1379@yahoo.com

${ }^{14}$ Non-Communicable Diseases Research Center, Alborz University of Medical Sciences, Karaj, Iran

Full list of author information is available at the end of the article

\section{Background}

Chronic inflammation happens through frequent stress factors such as poor diet and obesity [1] and it is recognized with high levels of serum inflammatory biomarkers the original author(s) and the source, provide a link to the Creative Commons licence, and indicate if changes were made. The images or other third party material in this article are included in the article's Creative Commons licence, unless indicated otherwise in a credit line to the material. If material is not included in the article's Creative Commons licence and your intended use is not permitted by statutory regulation or exceeds the permitted use, you will need to obtain permission directly from the copyright holder. To view a copy of this licence, visit http://creativecommons.org/licenses/by/4.0/. The Creative Commons Public Domain Dedication waiver (http://creativeco mmons.org/publicdomain/zero/1.0/) applies to the data made available in this article, unless otherwise stated in a credit line to the data. 
including high sensitivity C-reactive protein (hs-CRP), interleukin (IL)-6, and tumor necrosis factor- $\alpha$ (TNF$\alpha)$. This situation is associated with chronic outcomes including cardiovascular diseases (CVDs) [2], type 2 diabetes mellitus [3], cancer [4], obesity [5], and metabolic syndrome (MetS) and its components [6]. The association of diet with inflammation and CVDs is well demonstrated in previous studies. Adherence to Mediterranean diet, which is characterized by high intake of fruits and vegetables, whole grains, legumes, nuts, fish, and olive oil, decreases chronic inflammation and is associated with lower risk of CVDs [7-11], whereas intake of foods with high amount of sugar, refined grains, red and processed meat, foods with high saturated and trans fatty acids, and sodium (Western diet) is associated with higher levels of chronic inflammation and intermediate markers of CVDs [12].

The dietary inflammatory index (DII) is a novel and validated tool designed in 2009 [13] and updated in 2014 to estimate the inflammatory potential of an individual's diet [14]. According to this index, the food items, macronutrients, and micronutrients (45 food parameters) based on their effect on inflammatory biomarkers (IL-1 $\beta$, IL-4, IL-6, IL-10, TNF- $\alpha$, and CRP) were classified into pro-inflammatory, anti-inflammatory, and inflammatory neutral [14].

Multiple studies have assessed the association of the DII score with different chronic diseases [15-18] and their risk factors [19-23]; however, findings are conflicting. Various studies showed the association between the DII score and cardiometabolic risk factors (CMRFs) such as MetS [23], hypertension (HTN) [17, 24], and serum glucose levels [20], while other studies did not show this association [25-28]. Several observational reports have demonstrated the obvious association of the DII score with cardiometabolic diseases (CMDs)-specific morbidity and mortality $[15,19,29,30]$, whereas other studies failed to find any association [31, 32].

Given the inconsistent findings, this meta-analysis was conducted to summarize the association of DII with CMRFs and CMDs in observational studies.

Although recently some systematic reviews and metaanalyses have addressed the association between the DII score and CVDs morbidity and mortality [33-35] and MetS [34], none of them has evaluated the association of DII score with cardio-metabolic risk factors (e.g. lipid profile, glycemic indices, and anthropometric measures). Moreover, there is no comprehensive systematic review of assessing the association of both continuous and categorical DII score variables with CMRFs (e.g. lipid profile, glycemic indices, anthropometric measures, blood pressure (BP), and metabolic syndrome) and CMDs-specific morbidity and mortality. Therefore, the aim of this systematic review and meta-analysis study was to assess the association of both continuous and categorical DII score variables with risk of CMRFs and risk of CMDs and mortality.

\section{Methods}

We followed the Preferred Reporting Items for Systematic Reviews and Meta-Analyses (PRISMA) statement for reporting in the current systematic review and mateanalysis study (Additional file 1: Appendix S1).

\section{Search strategy}

Published reports with the aim of studying the association of DII score with CMRFs (e.g. glycemic indices, lipid profiles, anthropometric measures, MetS and its components) and CMDs (like MI, IHD, stroke, congestive heart failure, and coronary heart disease (CHD) according to the International Classification of Diseases (ICD)-9-390465) were included through comprehensive searches on PubMed and the NLM Gateway (for MEDLINE), Scopus, and Institute of Scientific Information (ISI) electronic databases up to February 2020. The appropriate medical subject headings, Entry Terms, and Emtree options were applied to carry out the most sensitive search operations. The search strategy is presented in Additional file 2: Appendix S2. A manual search was performed on Google Scholar database and the references listed in relevant reviews.

\section{Inclusion criteria}

Two reviewers (ZA and HA) independently reviewed and screened the appropriate published papers based on title, abstract, and full text. The third reviewer (MQ) resolved any discrepancy in choosing eligible records. All observational studies (cross-sectional, case-control, and cohort) on human subjects without restriction of age group, gender, year of publication, and language examining the association between the DII score with CMRFs (e.g. glycemic indices, lipid profiles, anthropometric measures, MetS and its components) and CMDs were included in the current study.

\section{Exclusion criteria}

The papers with the following conditions were excluded: (1) studies that considered the DII as a dependent variable, (2) letters, abstracts and reviews, and (3) duplicated publications. For multiple publications of the same population, only the article with the largest sample size was included.

The participants, intervention, comparators, outcomes, study design criteria are listed in Table 1. 


\begin{tabular}{ll}
$\begin{array}{l}\text { Table } 1 \text { Participants, } \\
\text { outcomes, study design } \begin{array}{c}\text { intervention, } \\
\text { of studies) }\end{array}\end{array}$ \\
\hline criteria for inclusion
\end{tabular}

\section{Data extraction}

Two investigators (ZA and SD) independently extracted the following information from each qualified study: first author, year of publication, study design, country, age range/mean age, gender, sample size, diet assessment tool, the number of subjects with abnormal CMRFs/ the number of subjects with CMDs, follow-up duration, exposure variable (DII/E-DII), and the number of food items used to calculate it, the type and definition of outcome, outcome assessment method, the type of DII score variable (categorical/continuous), and effect size, study quality, and confounders. Any disagreements were removed by the third author (MQ). Studies which reported correlation or beta coefficient, were included in the systematic review and they were not entered the meta-analyses.

\section{Quality assessment}

The quality assessment of included studies was performed by two independent reviewer using NewcastleOttawa Scale (NOS) [36]. This scale consists of three portions of the selection, comparability and outcomes/ exposures, and the studies earned maximum nine points. In the present study, the reports with seven or more stars were assumed to have high quality. Any discrepancy between reviewers was resolved by the third reviewer (MQ).

\section{Statistical analysis}

All observational studies with any reported effect size (odds ratio (OR), hazard ratio (HR), correlation, or Beta coefficient) were included in qualitative synthesis. Metaanalysis was performed only for studies which reported OR and HR.

In meta-analysis, we examined association of all types of DII [continuous (per one-unit increment), categorical (highest/lowest level) and dose-response association] with CMRFs and CMDs. Meta-analyses were performed separately for CMRFs morbidity, CMDs morbidity, and CMDs related mortality.

We performed random/fixed effects meta-analysis using maximally adjusted OR/HR with $95 \%$ confidence interval (CI). Heterogeneity among studies was assessed by $I^{2}$ [37-39]. There was between-study heterogeneity if $I^{2}>50 \%$ and $\mathrm{p}<0.1$ for the result of $\mathrm{Q}$ test. If the results showed the heterogeneity, a random-effects model (the DerSimonian-Laird estimator) was applied to assess the pooled OR/HR. The results of the meta-analyses were schematically presented by forest plots.

Dose-response meta-analysis was performed using a method suggested by Greenland and Orsini [40] to assess the dose-response association between DII score and CMDs related morbidity and mortality. The natural logs of the HRs and their CIs across categories of the DII score were used to compute study-specific slopes (linear trends). In this method, the distribution of cases and the HRs with the variance estimates for $\geq 3$ quantitative categories of exposure were required. We considered the median or mean values of the DII scores in each category to the corresponding HR for each study. For studies that reported the scores as ranges, the midpoint was estimated in each category by calculating the mean of the lower and upper bound. When the highest and lowest categories were open-ended, the length of these openended intervals was assumed to be the same as that of the adjacent intervals. Restricted cubic splines (three knots at fixed percentiles of $10 \%, 50 \%$, and $90 \%$ of the distribution [41]) was used to examine potential nonlinear doseresponse associations of the DII score with risk of CMDs and mortality.

Publication bias was examined using Egger test and funnel plots. Subgroup analysis according to the type of study design was used to examine the association between the DII score with risk of CMDs and mortality. Sensitivity analysis was performed to assess the effect of removing any of the studies or group of studies on CMDs and CMRFs. All statistical analyses were performed using Stata software version 12 (Stata Corp, College Station, Texas, USA) and p-value $<0.05$ was considered statistically significant.

\section{Results}

\section{Search results and study selection}

A flow diagram for the process of study selection is shown in Fig. 1. The initial search recognized 1,535 papers, and 708 of them remained after duplicate exclusion. Then 653 papers were removed after examining title/abstract and full text of records. The papers were investigated according to the inclusion and exclusion criteria. Eventually, 55 studies were included in the systematic review [15-17, 19-32, 42-79] and 32 records (16 records for CMRFs $[17,19,20,23-26,28,58,61,62,68$, $70,72,73,76]$ and 18 records for CMDs [15-17, 19, 29$32,51-57,77-79])$ were selected for meta-analysis. Two studies addressed the association between the DII score and both CMRFs and CMDs outcomes [17, 19]. Due to 


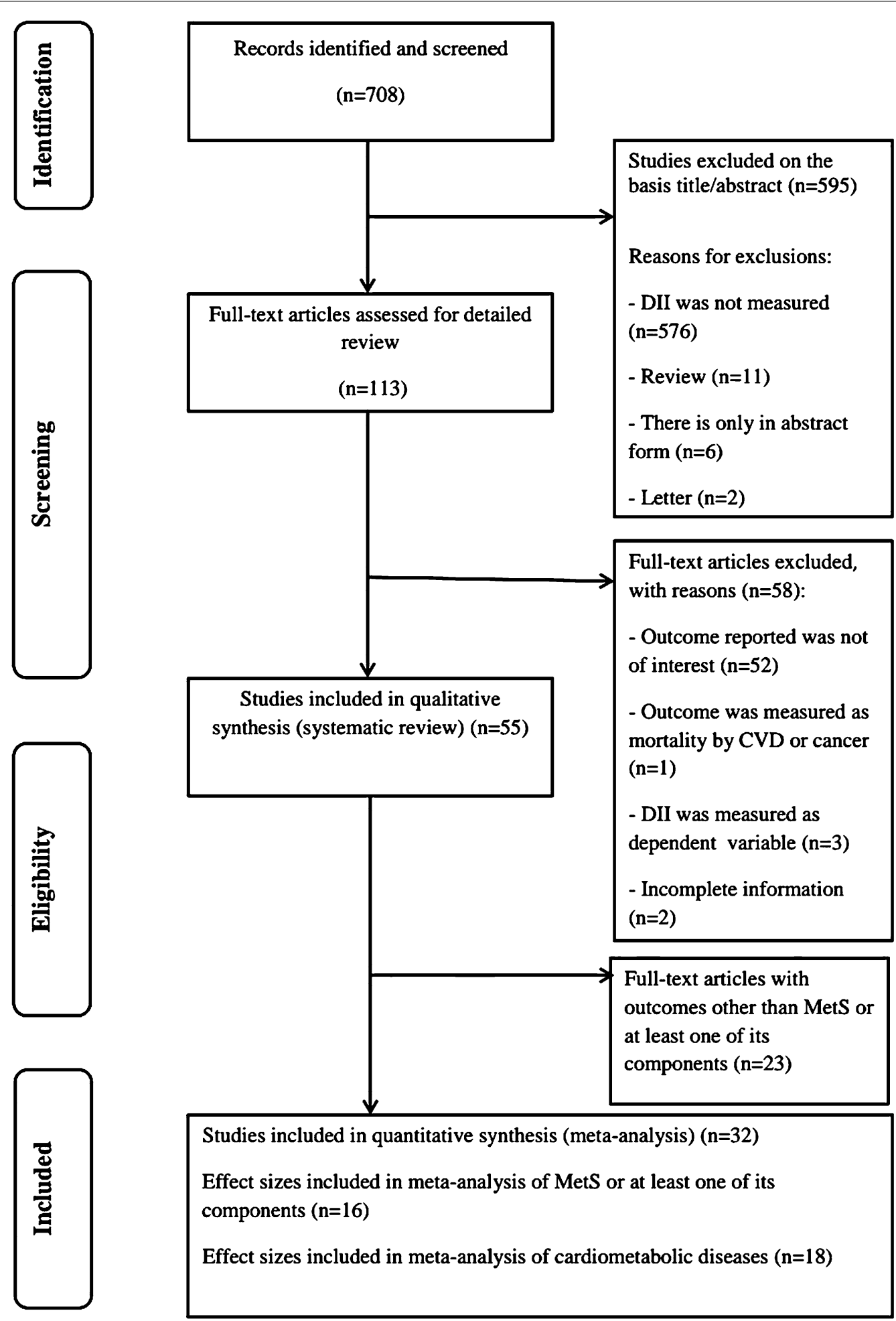

Fig. 1 Flow chart of study selection process 
various outcomes of CMRFs, we considered only studies reporting OR along with $95 \%$ confidence interval (CI) for MetS or its components in the meta-analysis.

\section{Study characteristics}

Overall, 55 eligible publications were included in the study. Tables 2 and 3 show the general characteristics of included studies. In general, nine and 10 surveys had considered the morbidity [15-17, 19, 30, 32, 52, 53, 57] (the range of HR was 0.98 [32] to 2.03 [17]) and mortality $[29-31,51,54-56,77-79]$ (the range of HR was 0.98 [51] to 2.50 [78]) of CMDs as outcome, respectively. In addition, 39 studies addressed the association between the DII score and CMRFs [17, 19-28, 42-50, 58-76]. Four case-control studies [15, 21, 57, 74], 23 cohort studies [16, 17, 22-24, 27, 29-32, 44, 45, 48, 51-56, 59, 77-79], and 28 cross-sectional studies [19, 20, 25, 26, 28, $42,43,46,47,49,50,58,60-73,75,76]$ were included. The number of subjects included in the studies ranged from 90 [48] to 83,054 [79]. The age range of participants was 3-97 years. All records were published between 2014 and 2019. The included studies were conducted in Sweden [15, 45, 55], Australia [24, 29, 32, 53, 77], USA $[19,20,27,44,46,50,51,54,56,70,78,79]$, France [23, 52], Spain [16, 17, 22, 47, 49, 63, 69], Germany [31], Italy [57], England [30] Luxembourg [26, 42], Iran [21, 43, 58, 60, 65, 71, 73, 74], Lebanon [25] Korea [68, 75], Poland [28], Myanmar [72], Ireland [62], China [76], Mexico [64], Indonesia [66], Pakistan [67], Brazil [59, 61], and Colombia [48]. The maximum duration of follow up in cohort studies was 25.8 years [31]. Of total included studies, eleven studies were performed on women [24, 27, 29, $32,50,54,55,59,72,74,75]$ three on men $[31,53,67]$ and 41 reports contained both men and women [15-17, 19-25, 28, 30, 42-49, 51, 52, 56-58, 60-66, 68-71, 73, 76-79]. Validated food frequency questionnaire (FFQ) was applied to assess dietary intakes in 36 studies [15-17, 20-22, 24-30, 32, 42-45, 47, 49, 50, 53-55, 57, 58, 60-62, $64-66,71,73,74,77,79], 24-\mathrm{h}$ recall in 13 surveys [16, $19,46,51,56,59,67-70,75,76,78], 72$ - hour recall in one study [63], 24-h recall and FFQ in one report [72] and record in four studies [23, 31, 48, 52]. The exposure variable was considered categorical in 42 studies [15-17, 19-26, 28-32, 43, 46, 48, 51-58, 60, 62, 64, 65, 67, 68, 70, 72-79] and continuous in 32 studies [16, 19, 21, 28-32, $42-45,47,49,50,52,54-61,63,66,69,71,74,76,78,79]$.

\section{Results of qualitative synthesis}

\section{Association between the DII score with risk of CMDs} and mortality

The positive association between the DII score (as a continuous variable) and risk of CMDs and mortality was observed in three $[16,19,57]$ and six $[29,30,54,56,78$,
79] studies, respectively. Moreover, three records did not indicate the significant association between the DII score and risk of CMDs [31, 32, 52]. In addition, two studies failed to find any significant association between the DII score and risk of CMDs mortality [31, 55].

The DII score (as a categorical variable) was associated significantly with the risk of CMDs in six studies [15-17, $19,53,57]$ and seven reports showed the positive association between the index and risk of CMDs mortality [29, 51, 54, 56, 77-79]. Furthermore, three studies did not demonstrate any significant association between the DII score and risk of CMDs [31, 32, 52]. Moreover, three studies reported no significant association between this index and risk of CMDs mortality [30, 31, 55]. In one study, a significant association was observed between the DII score and risk of CMDs mortality only in normal and pre-diabetic participants [51].

\section{Association between DII with CMRFs}

Totally, 39 studies (28 cross-sectional study [19, 20, 25, $26,28,42,43,46,47,49,50,58,60-73,75,76]$, nine cohort study [17, 22-24, 27, 44, 45, 48, 59] and two case-control studies [21, 74]) had assessed CMRFs as an outcome [17, 19-28, 42-50, 58-76].The lowest and highest reported ORs were observed for the association between the DII score and abdominal obesity [OR: 0.58 (95\% CI 0.16, 2.05)] [58] and morbidity of pre-diabetes [OR: 18.88 (95\% CI 7.02, 50.82)] [21], respectively. Nine studies reported no association between the DII score and abdominal obesity $[20,25,26,28,58,68,72$, $73,76]$. Two reports illustrated a significant association between the DII score and low level of high-density lipoprotein cholesterol (HDL-C) [26, 28], whereas six studies failed to find this association $[20,25,58,68$, $73,76]$. With respect to hypertriglyceridemia, eight studies reported no association between this score and hypertriglyceridemia $[20,25,26,28,58,68,73,76]$. The DII score was associated with HTN in five studies $[17,19,24,70,76]$ and eight studies did not show any significant association [20, 25-28, 58, 68, 73]. Moreover, one study reported no association between the DII score and gestational HTN [27]. Six studies reported no association between the DII score and hyperglycemia $[25-28,58,76]$, whereas two studies revealed this association [20,73]. Another study indicated a positive association between this score and hyperglycemia only in men [68]. Also, four studies reported a positive association between the DII score and MetS [23, 62, 70, 73]; six studies reported no association in this regard $[20,25,26,28,61,76]$. Moreover, one study demonstrated a significant association between this score and MetS only in men [68]. In terms of body mass index (BMI), four studies showed no association between the 


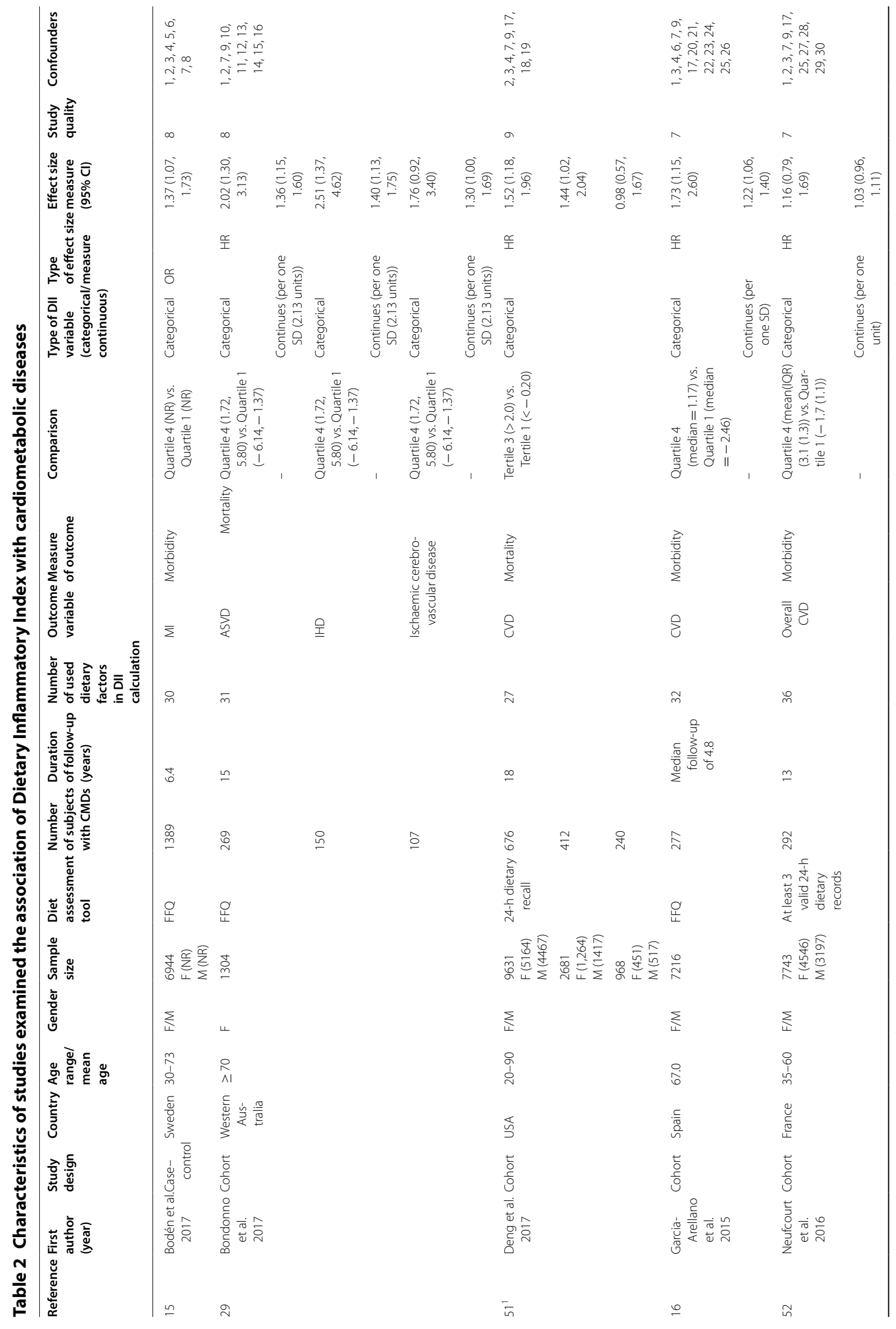




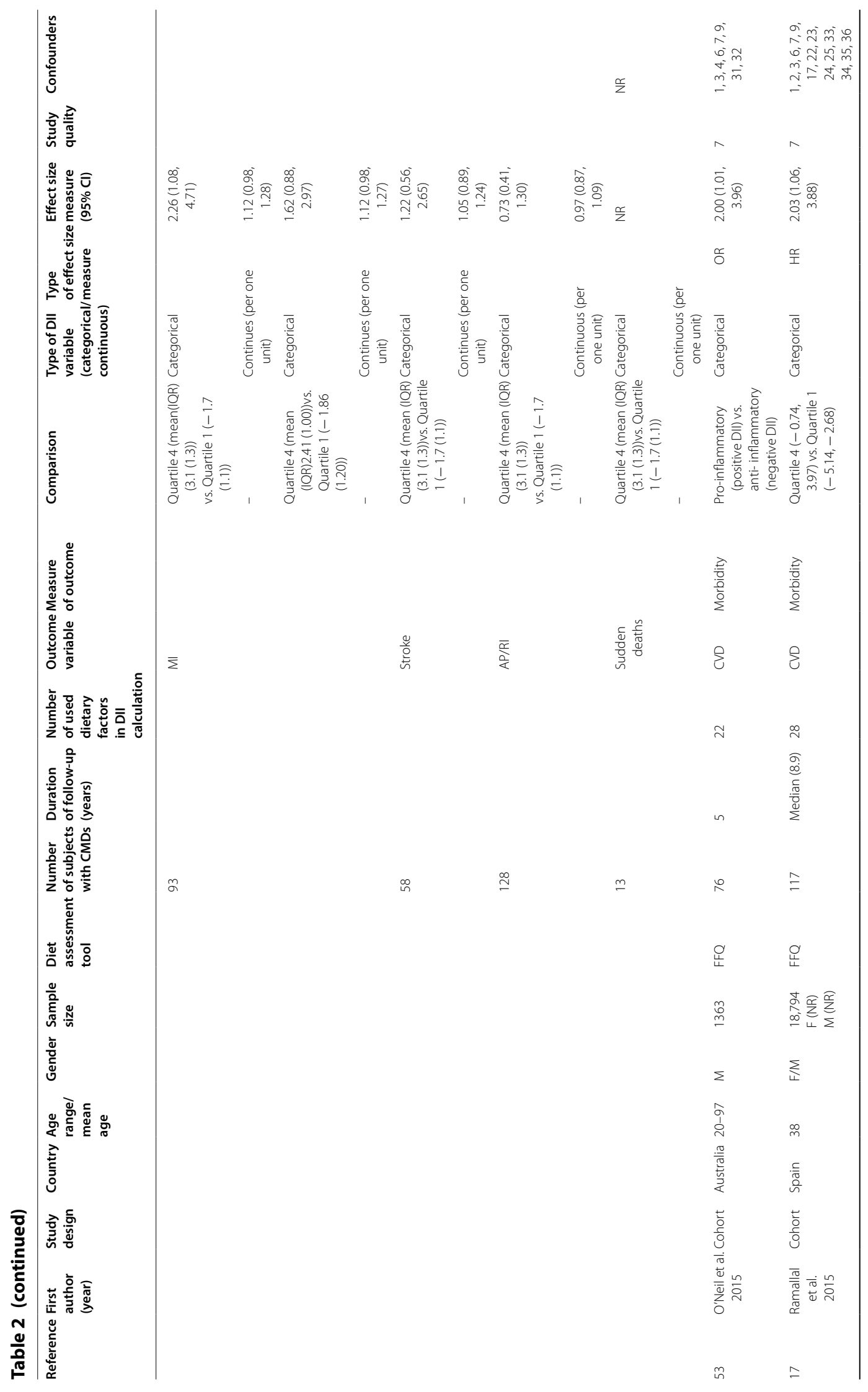




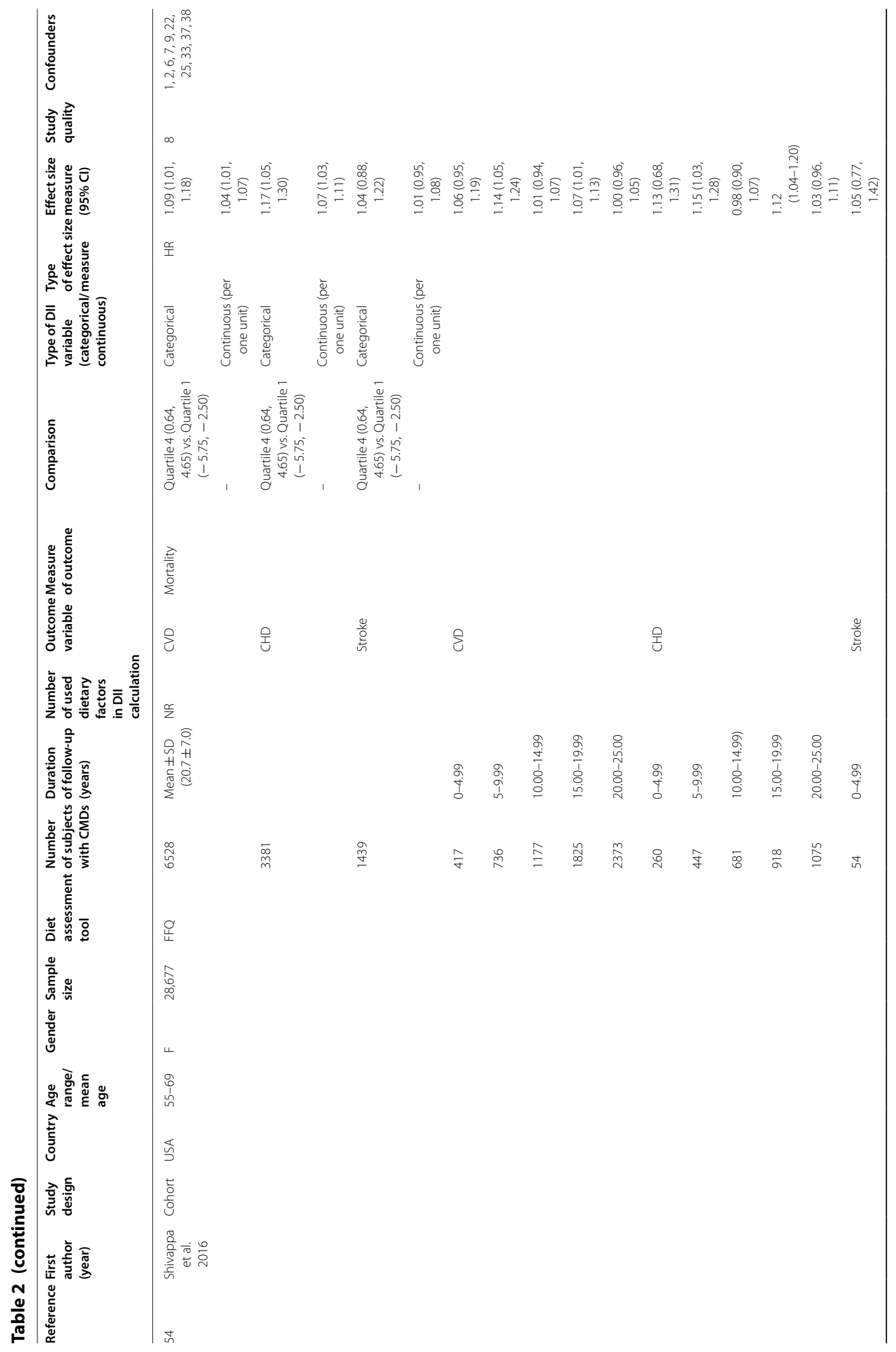




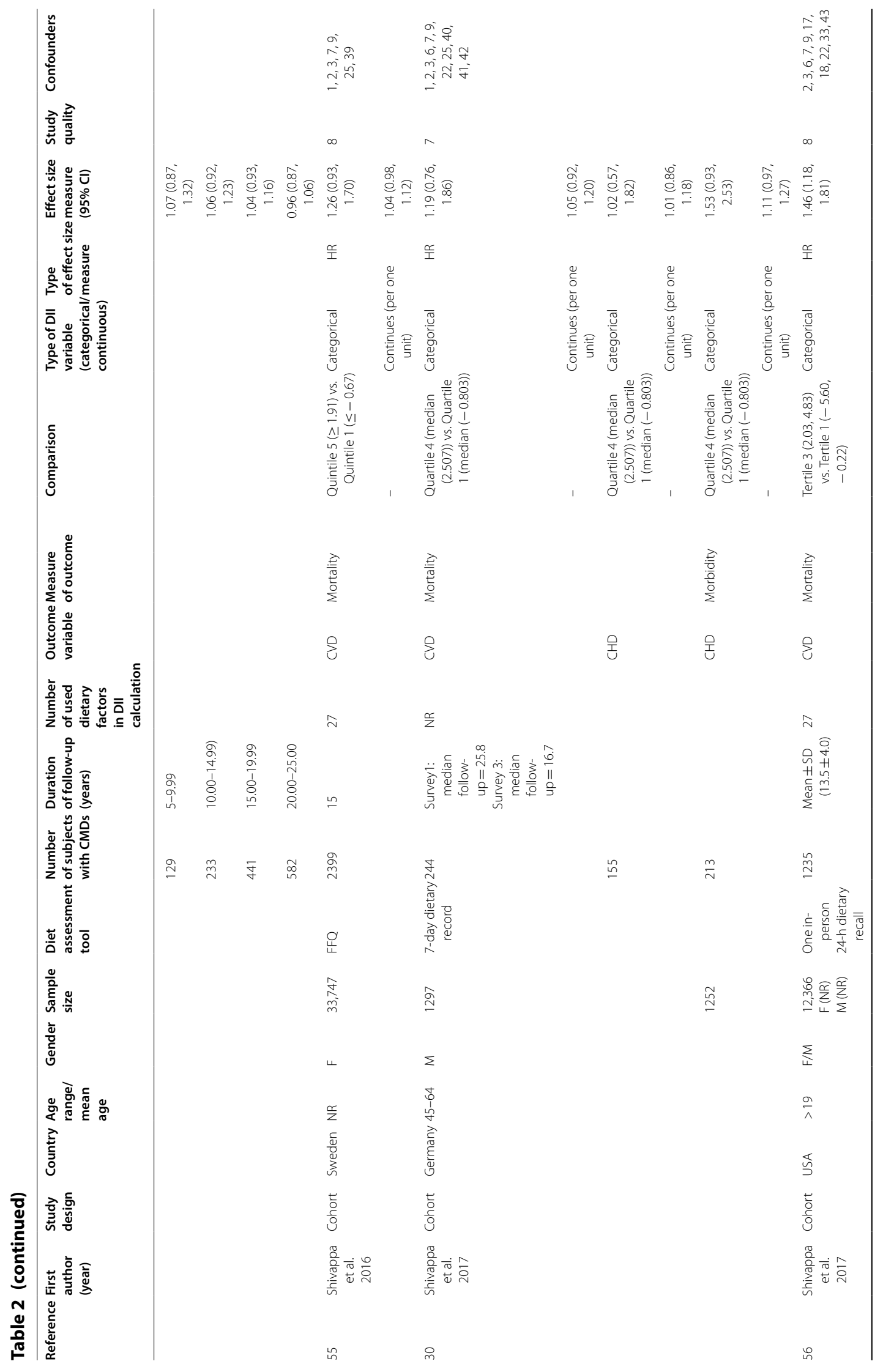




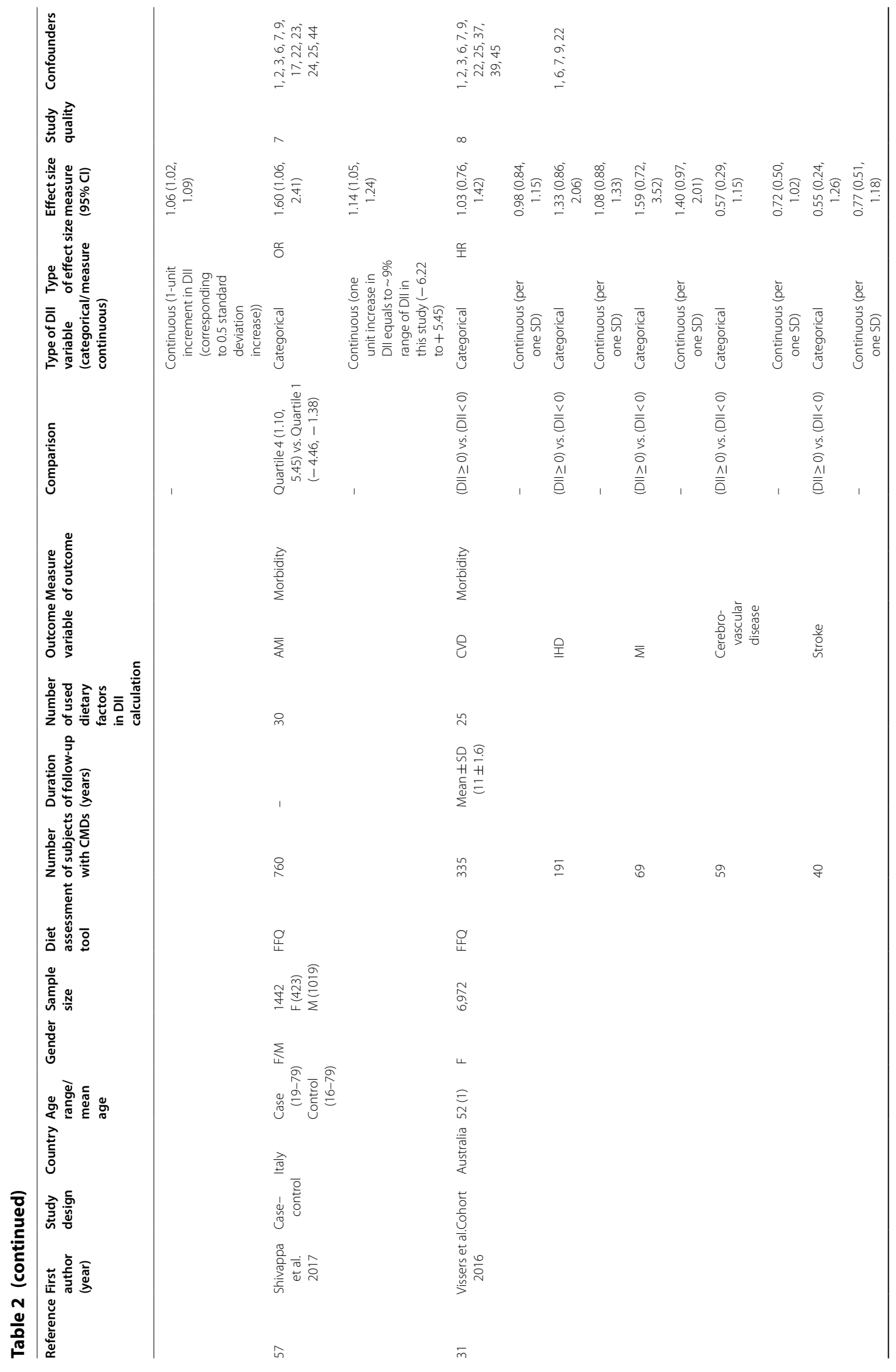




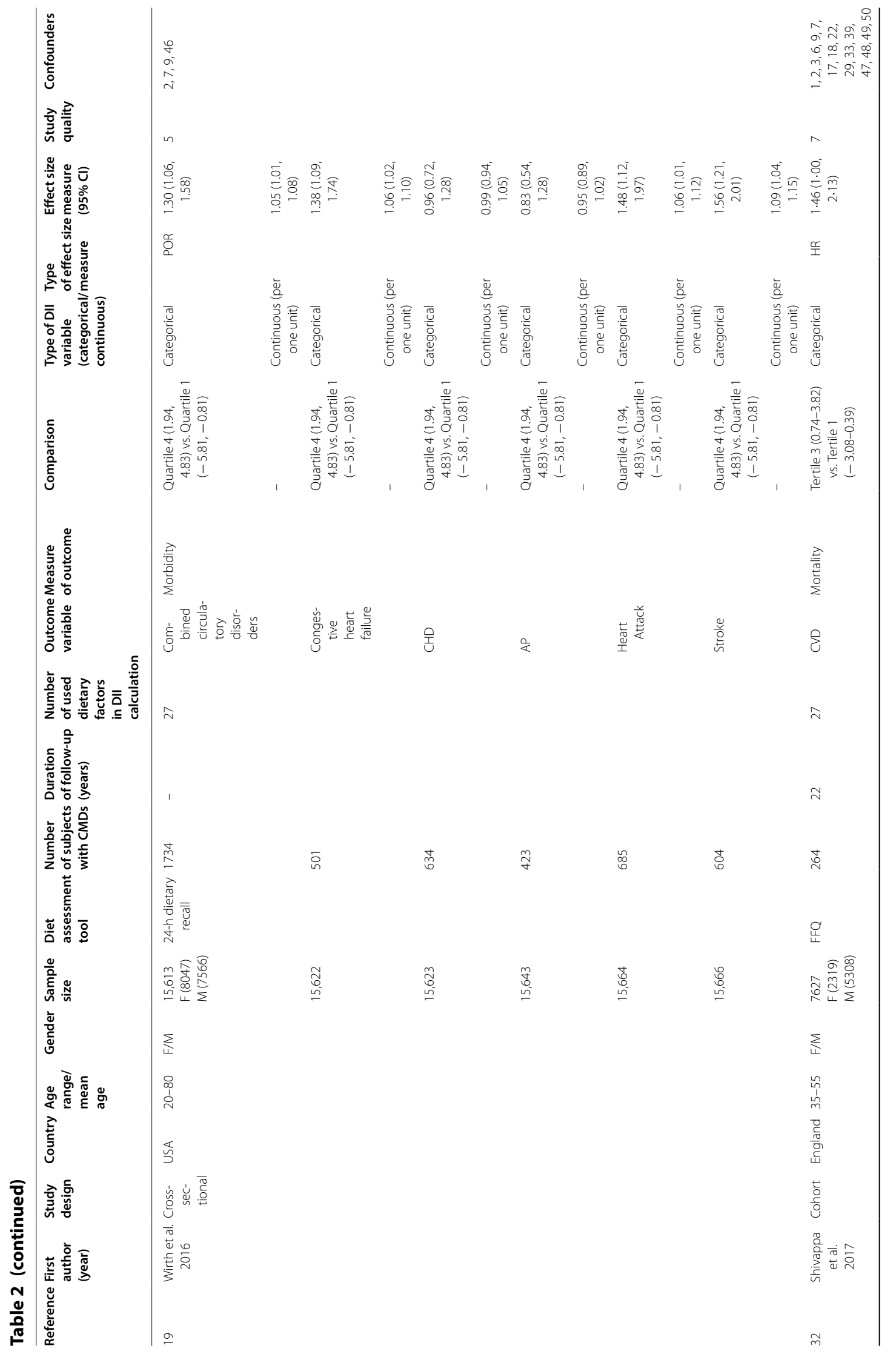




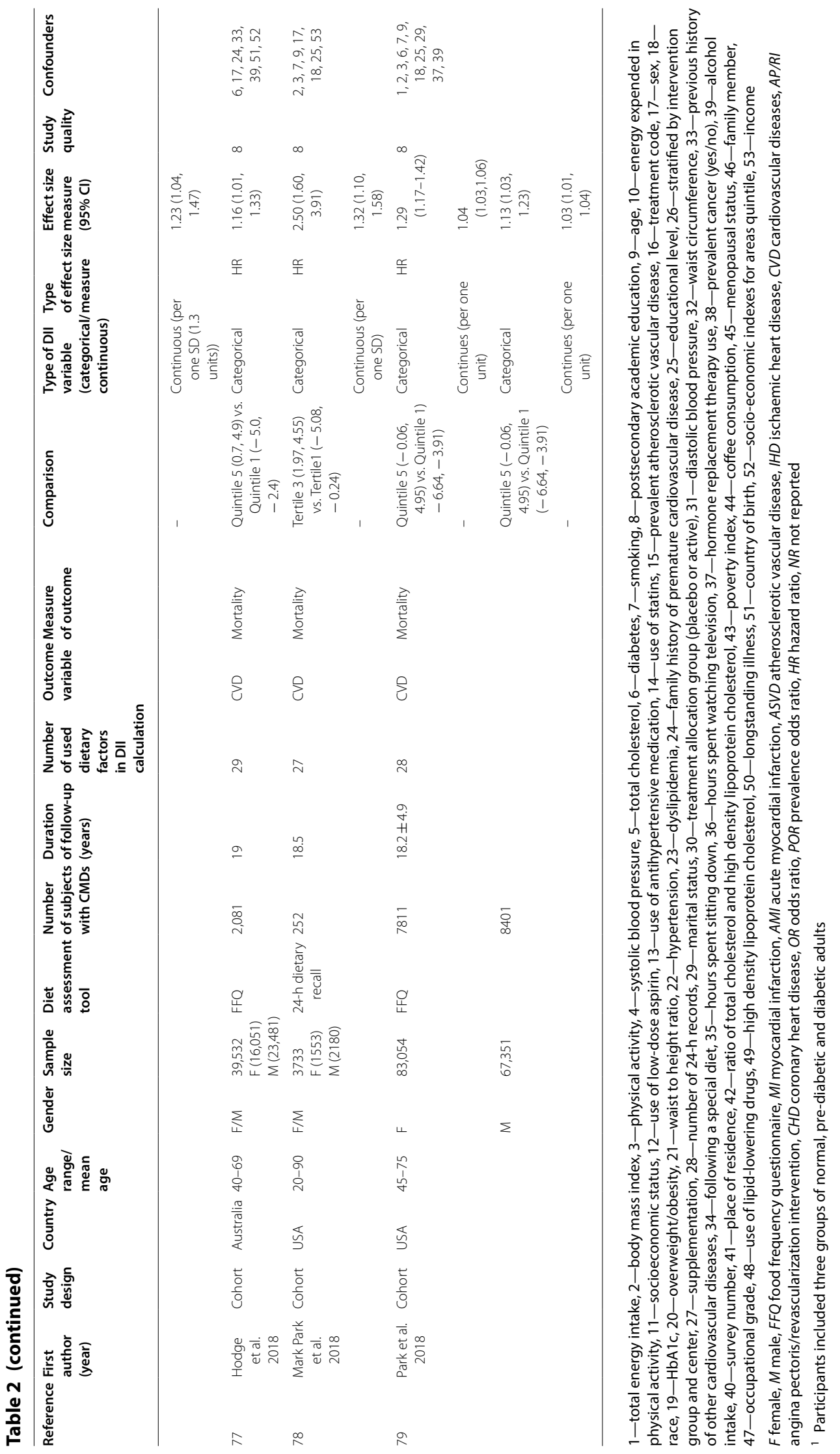




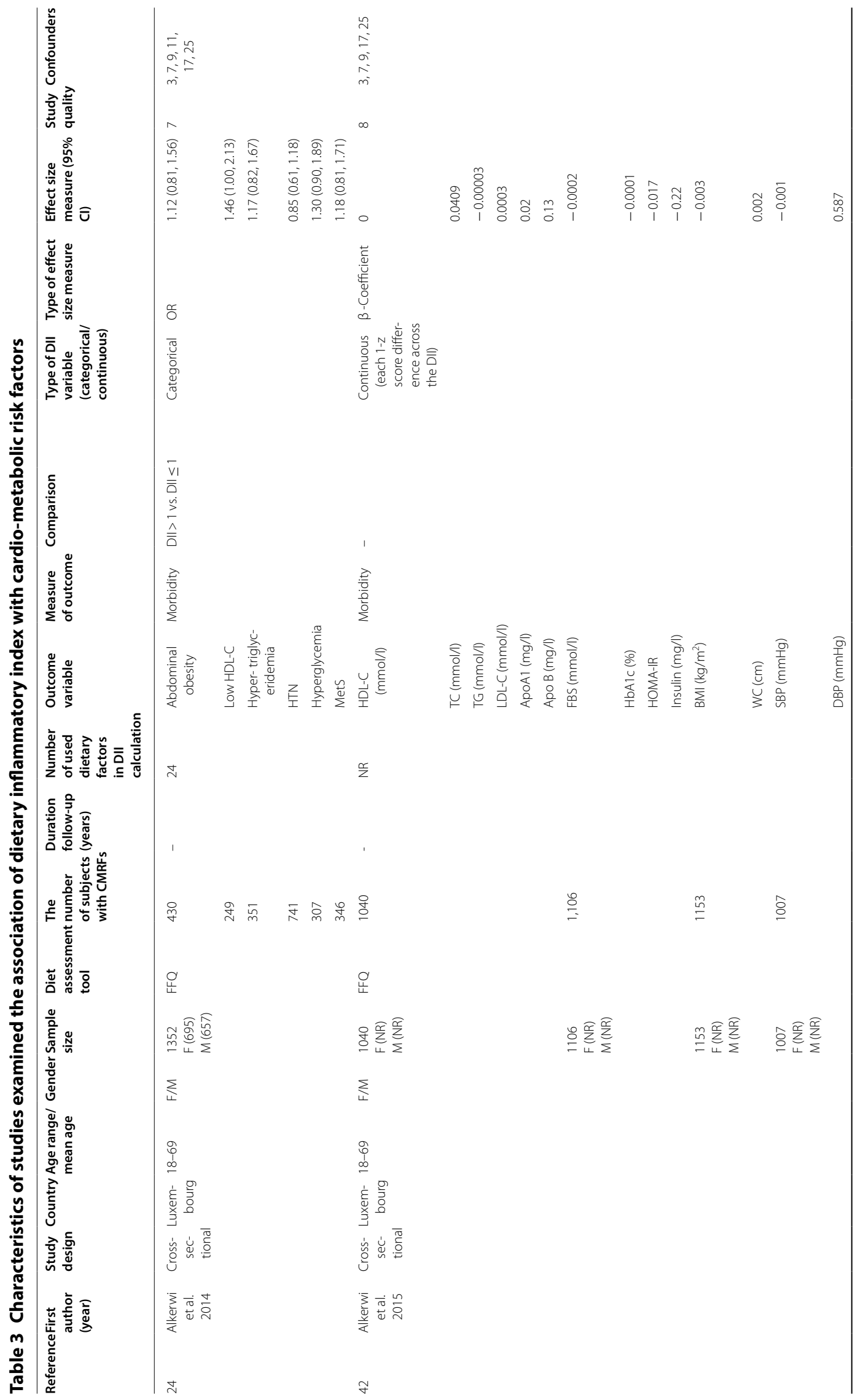




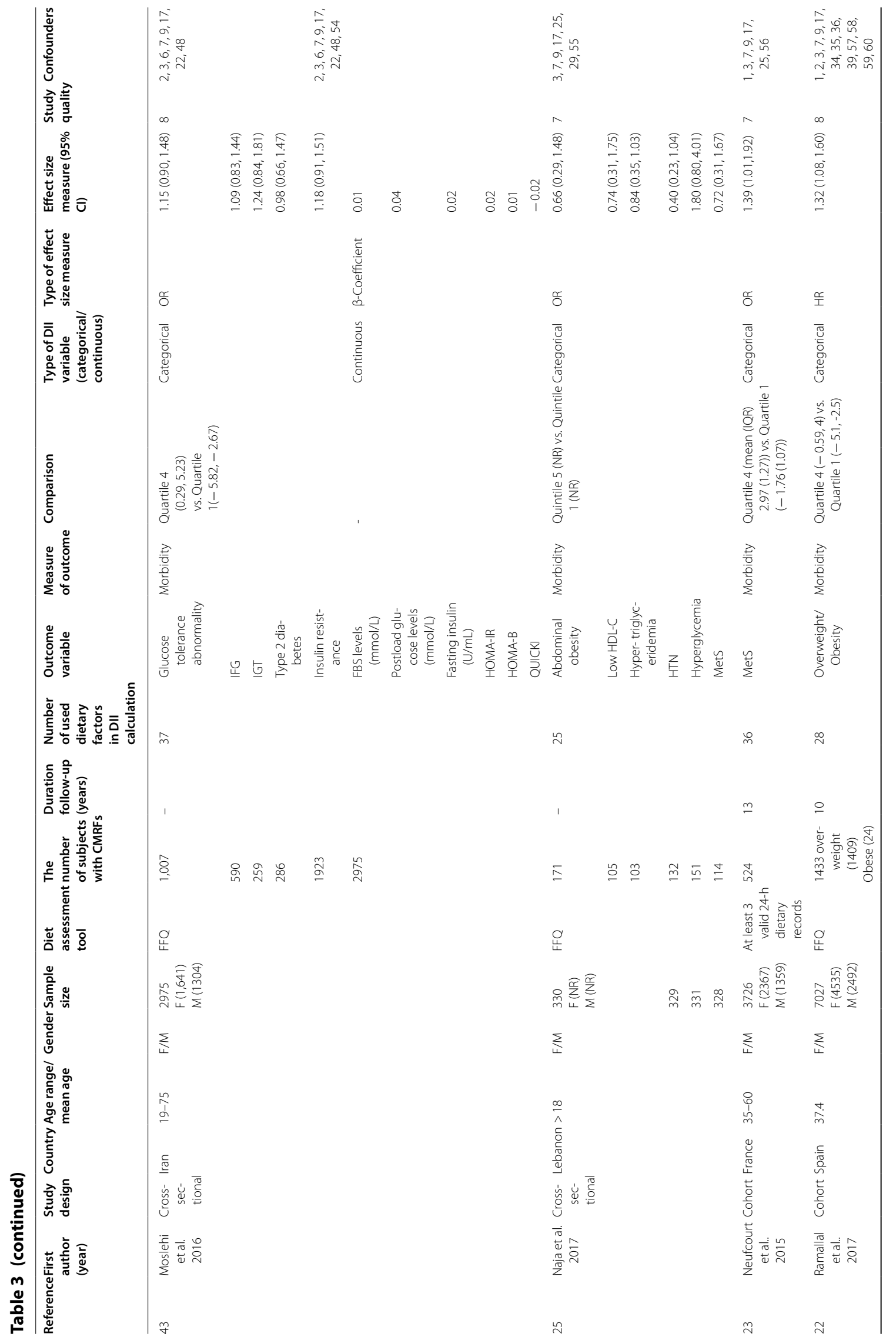




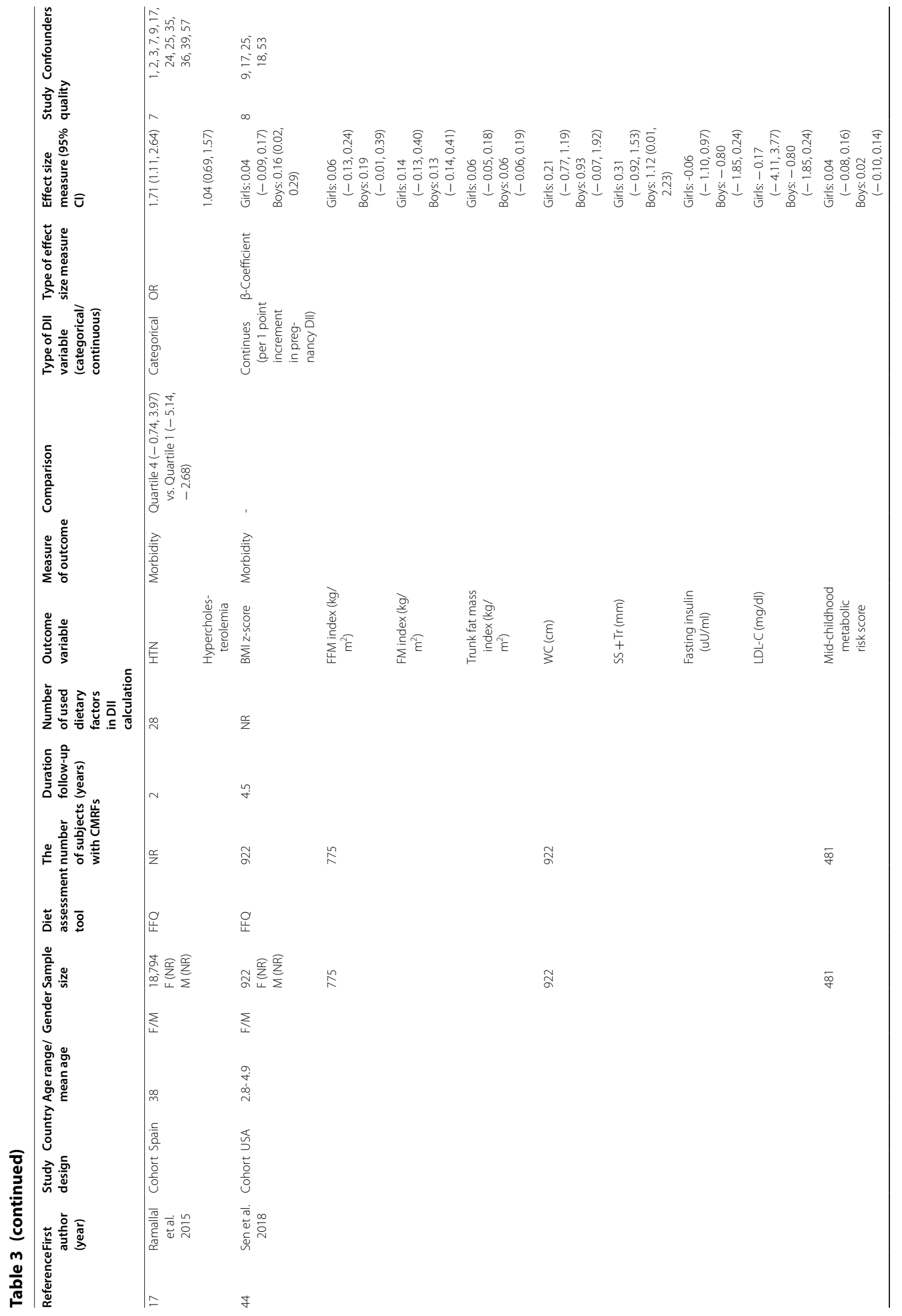




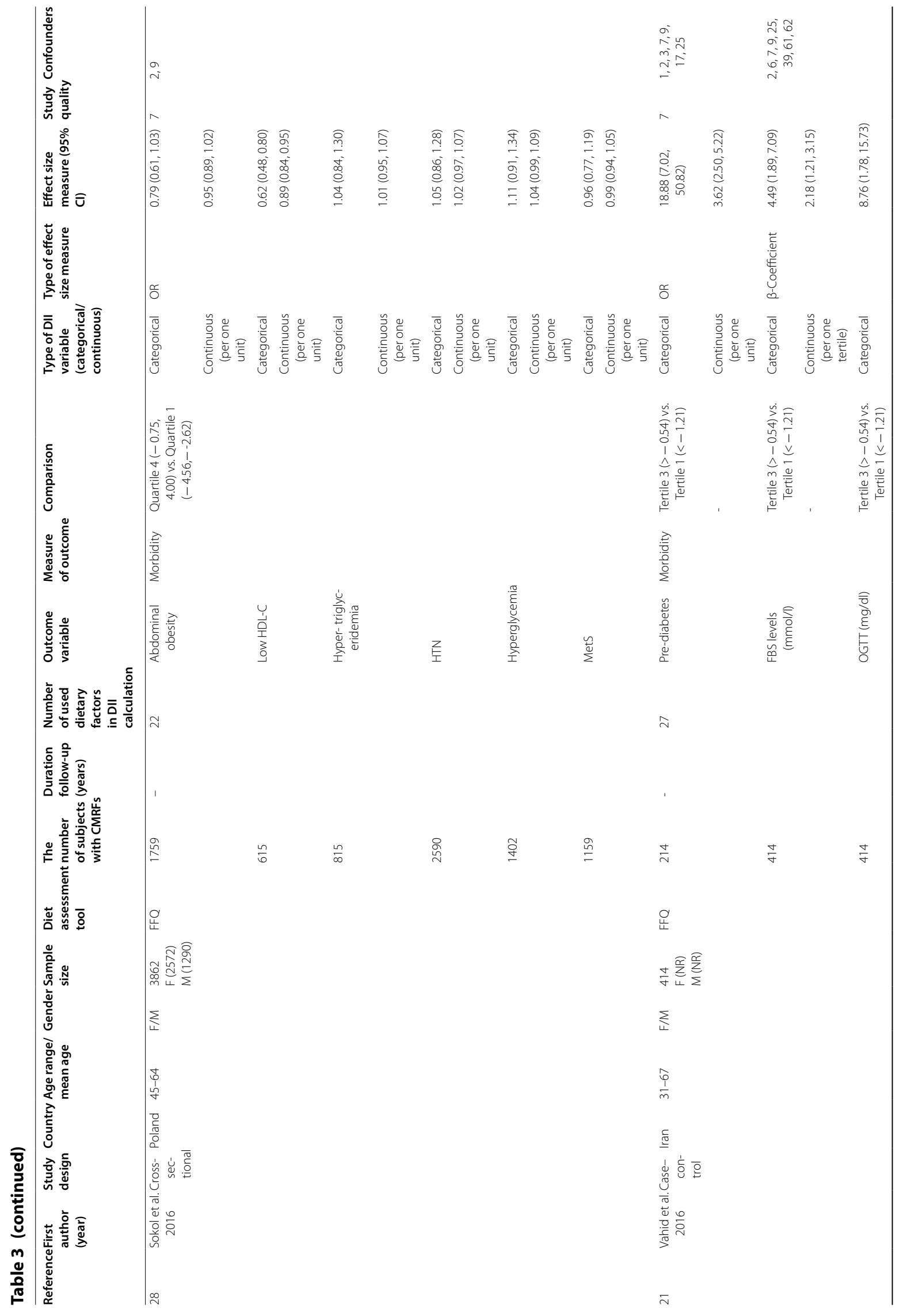




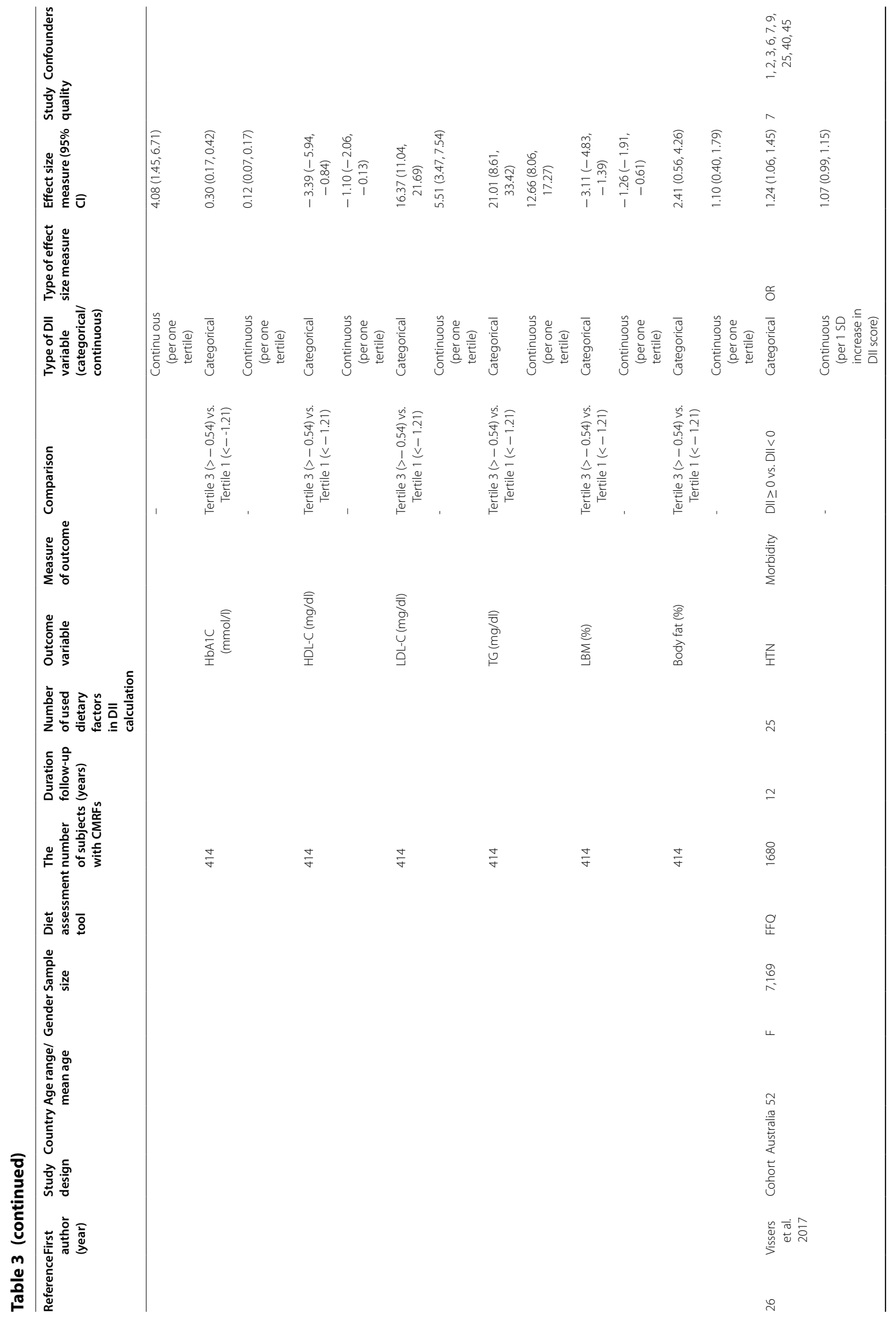




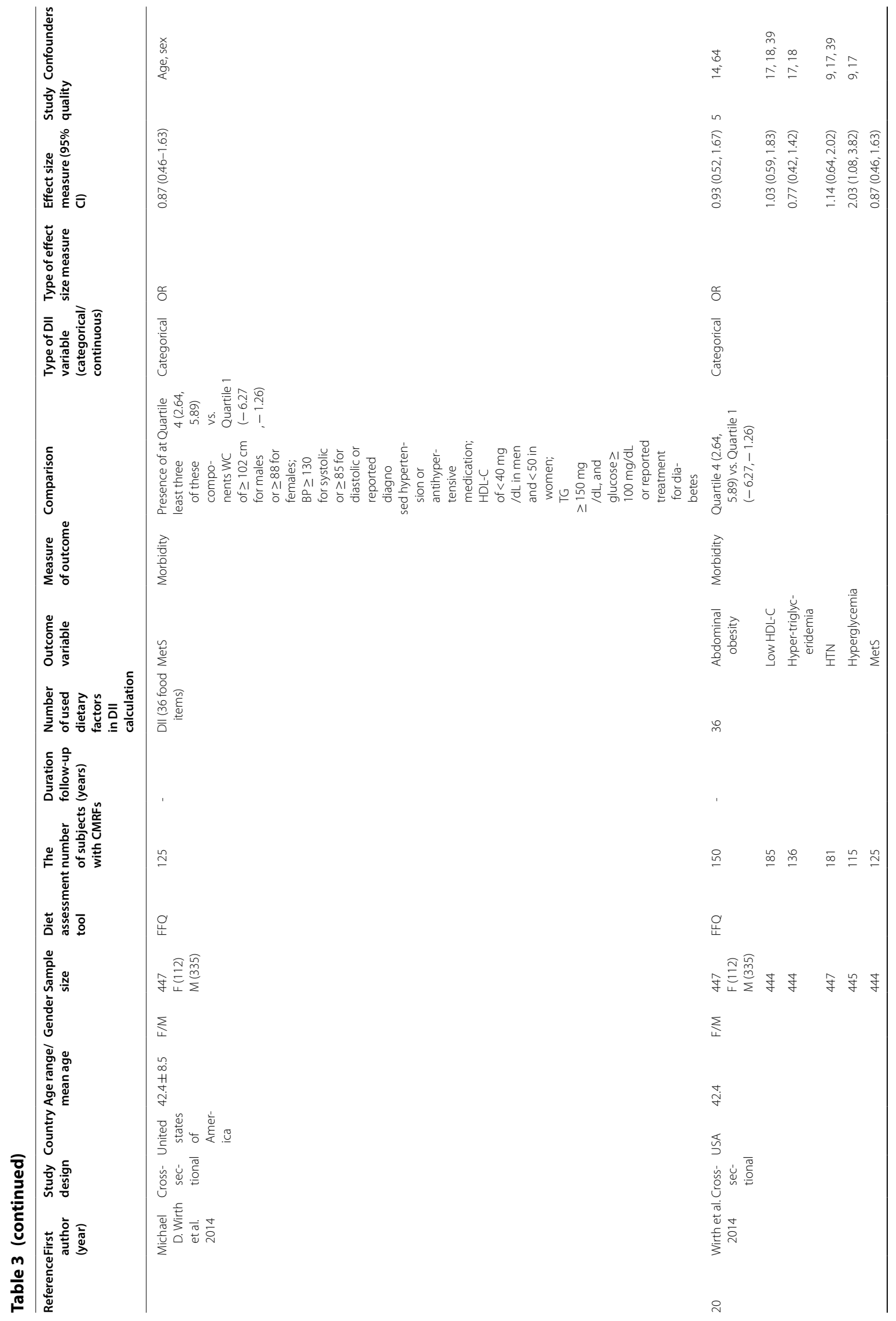




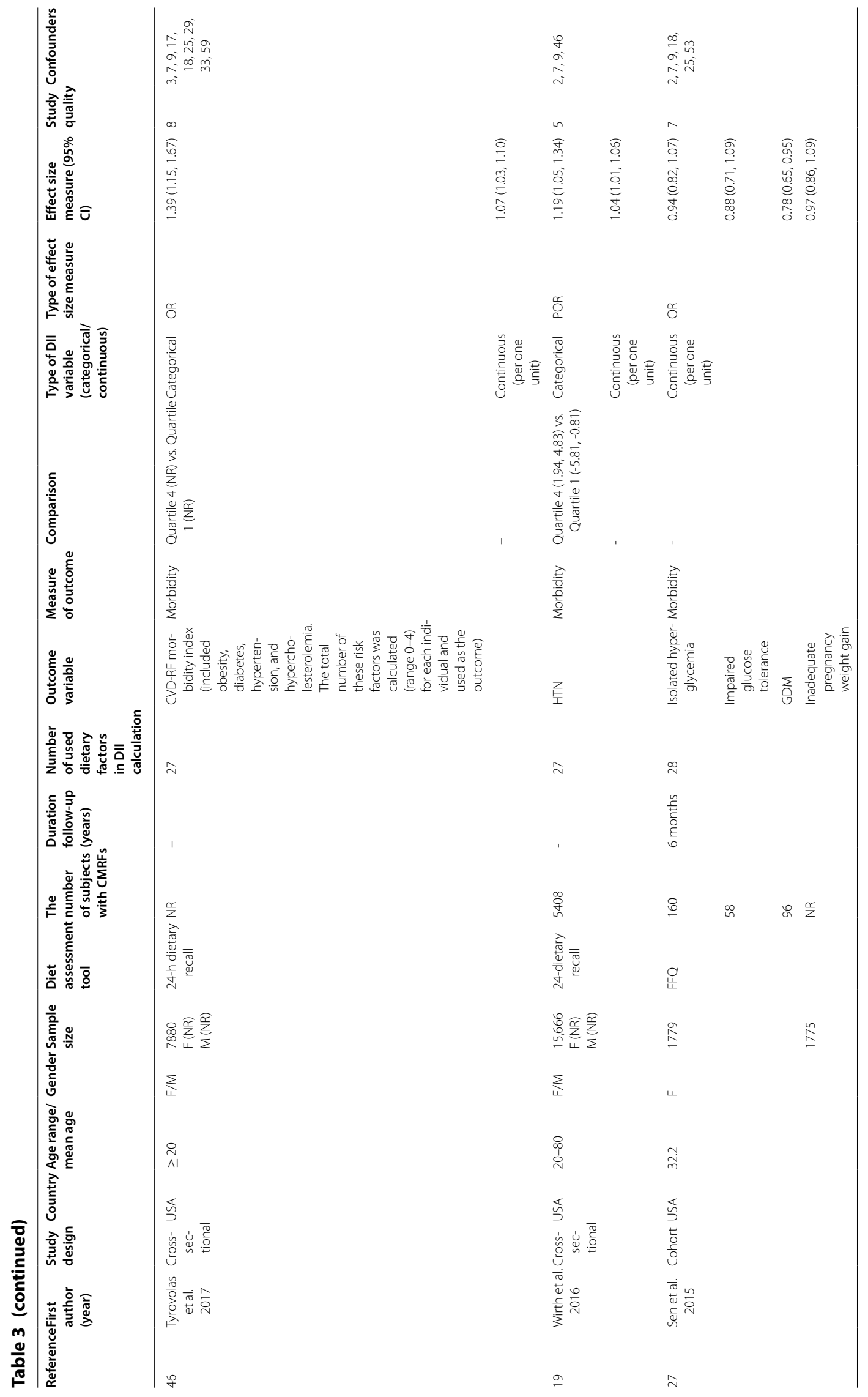




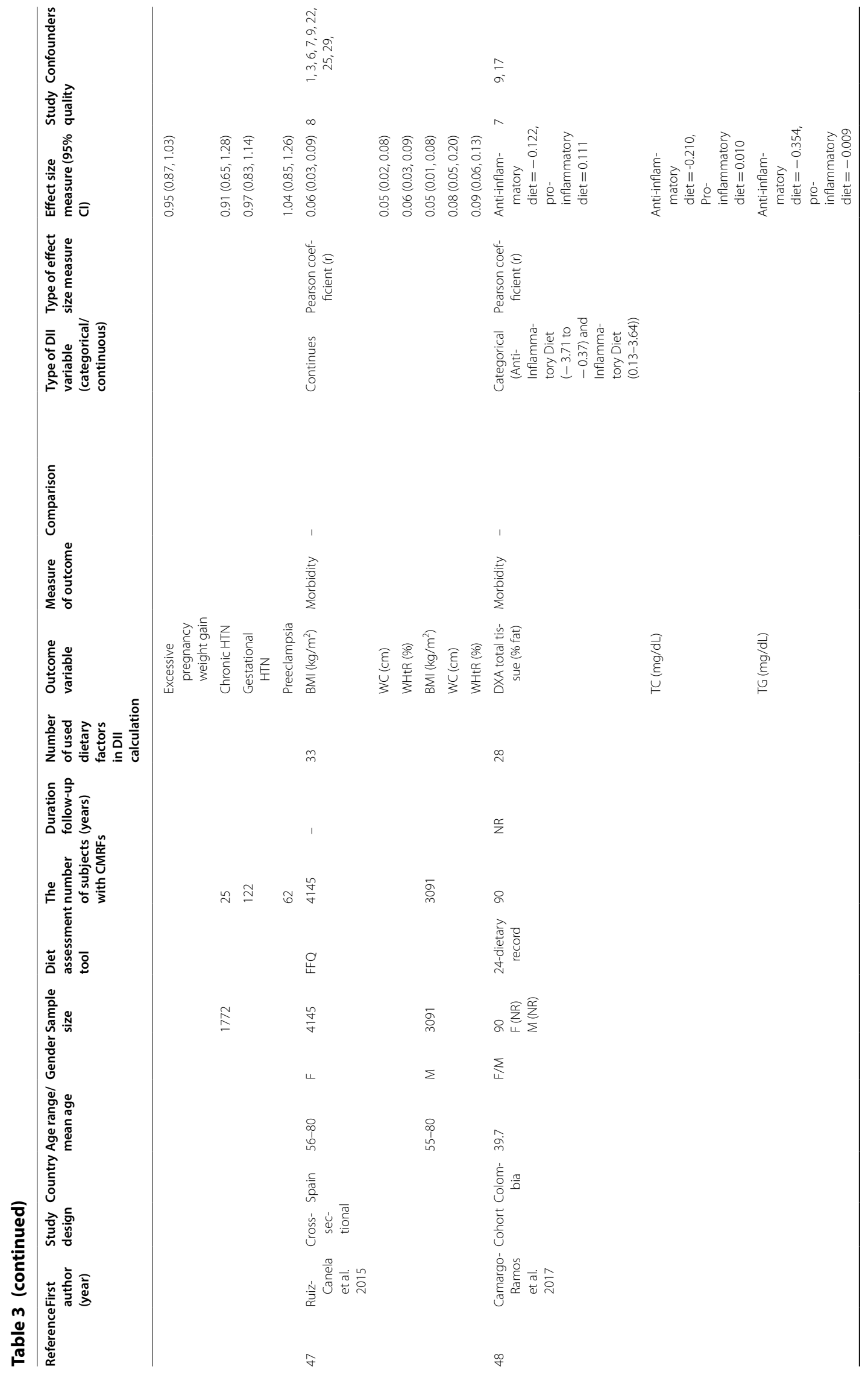




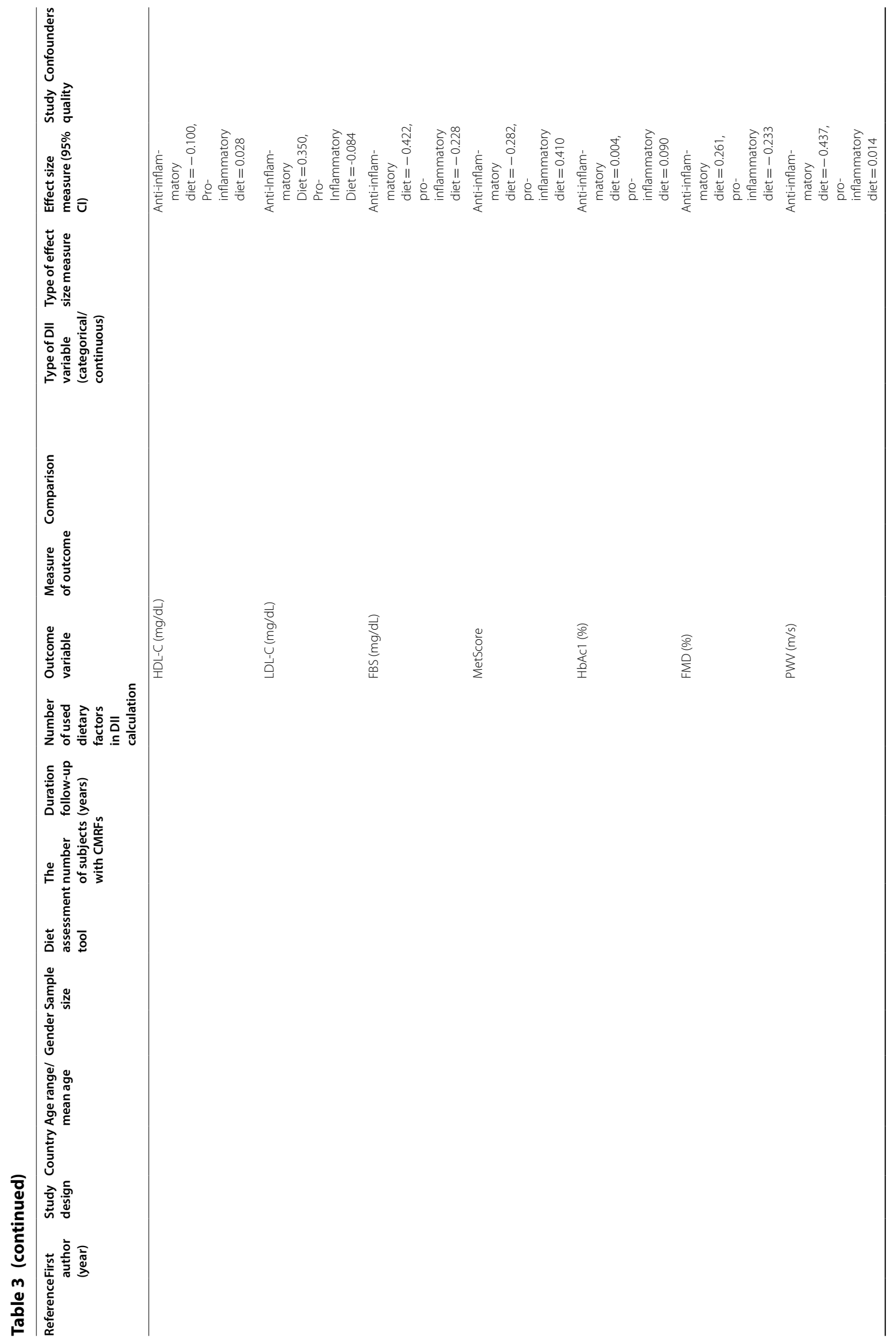




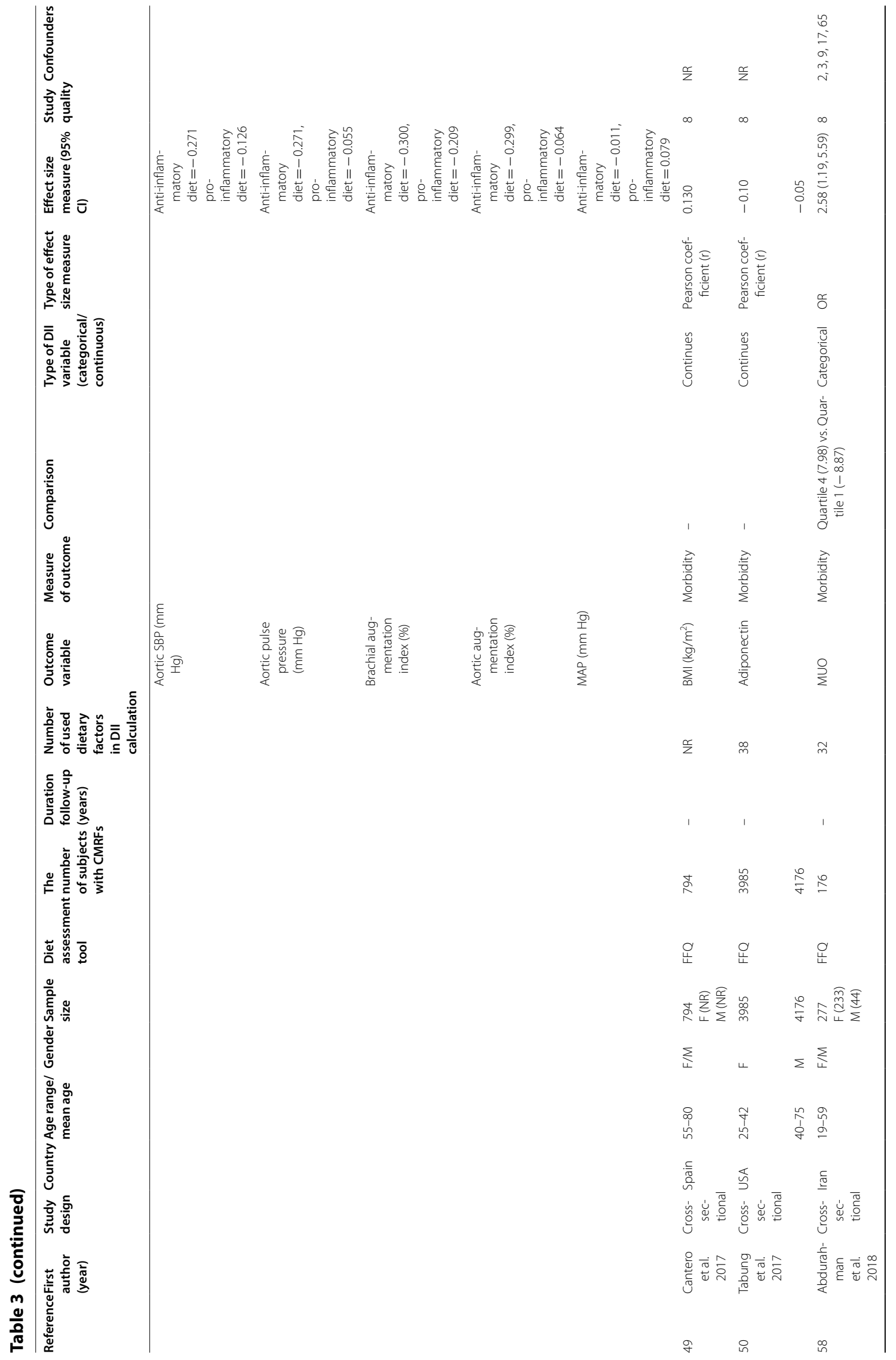




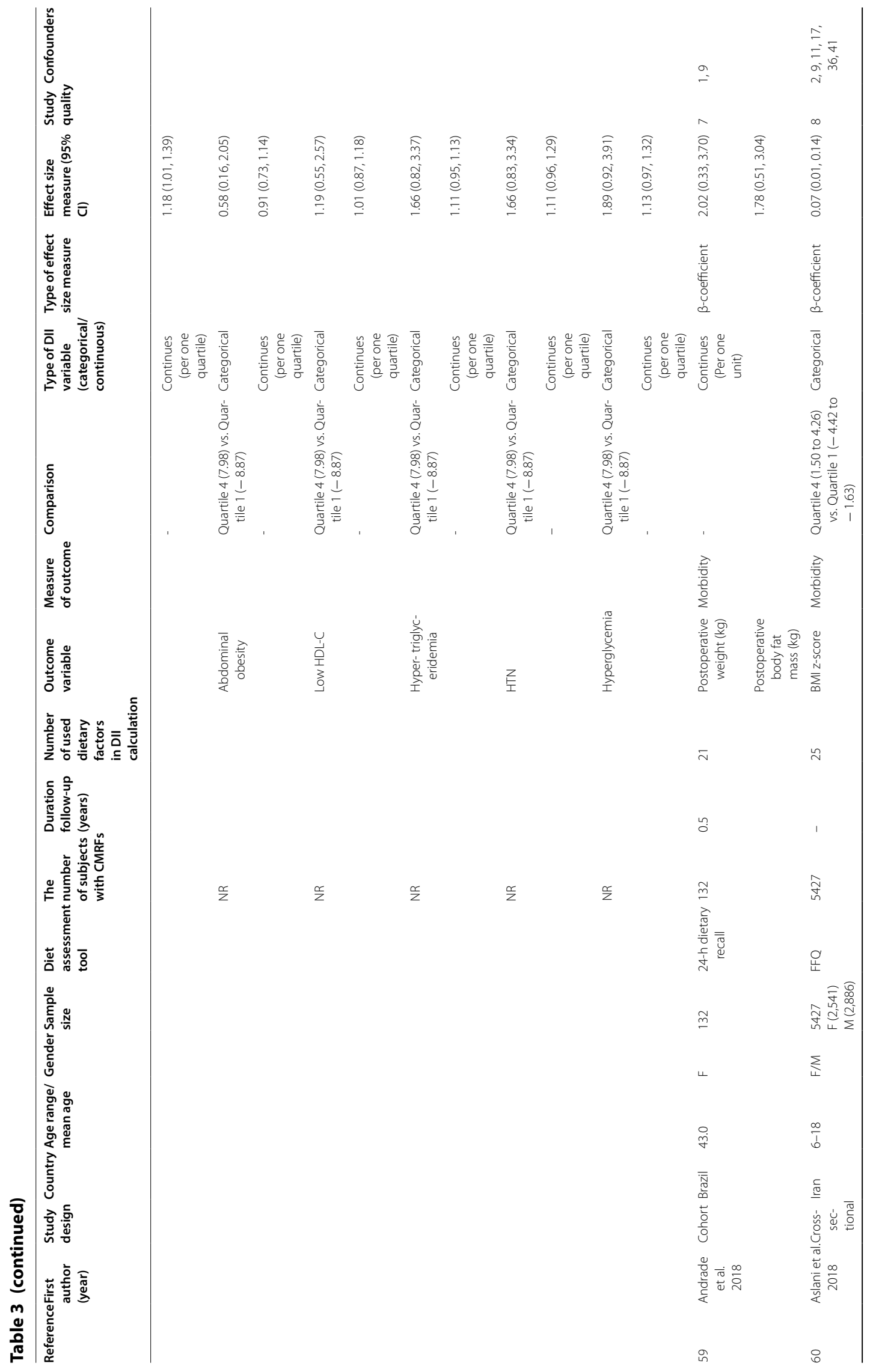




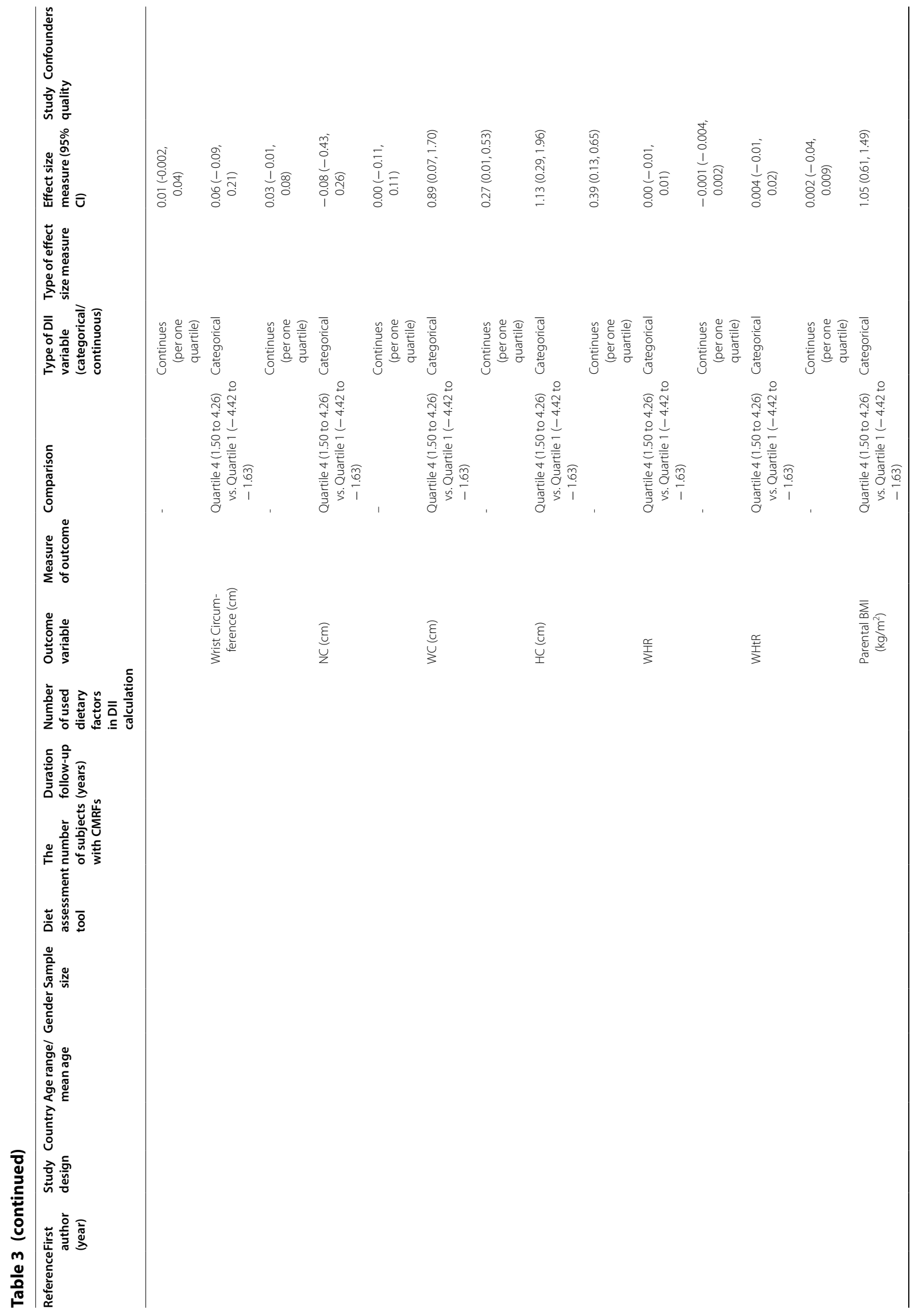




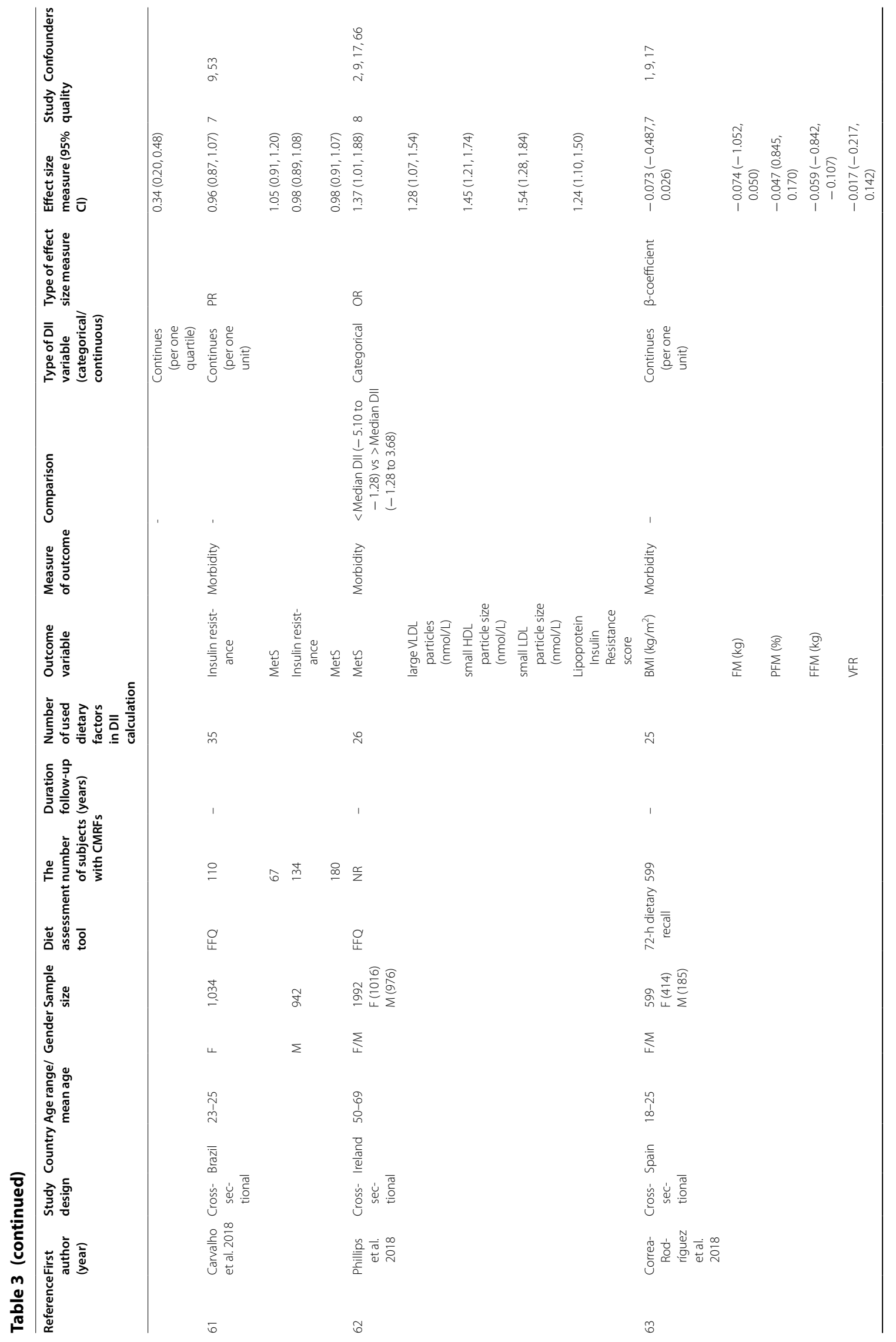




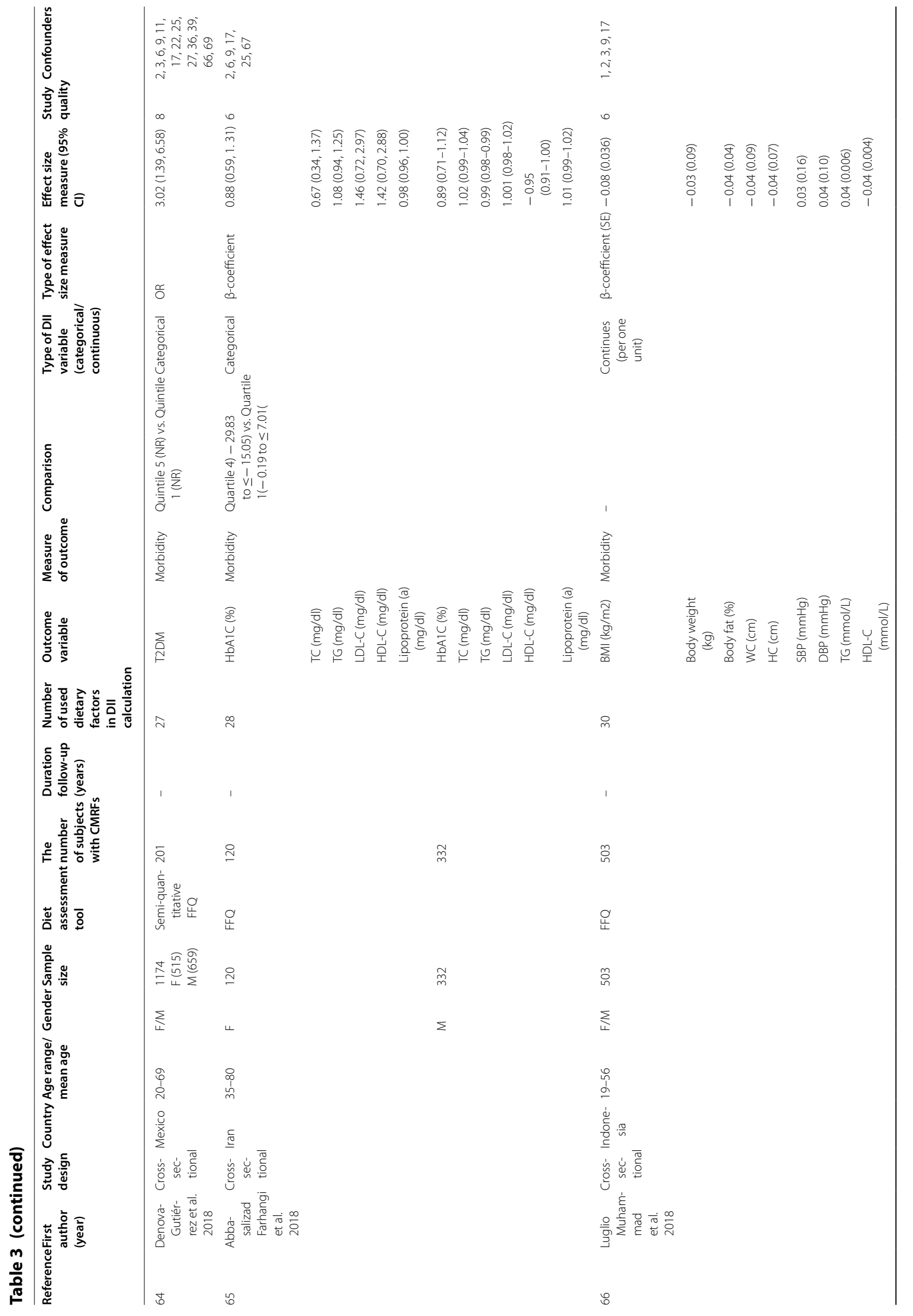




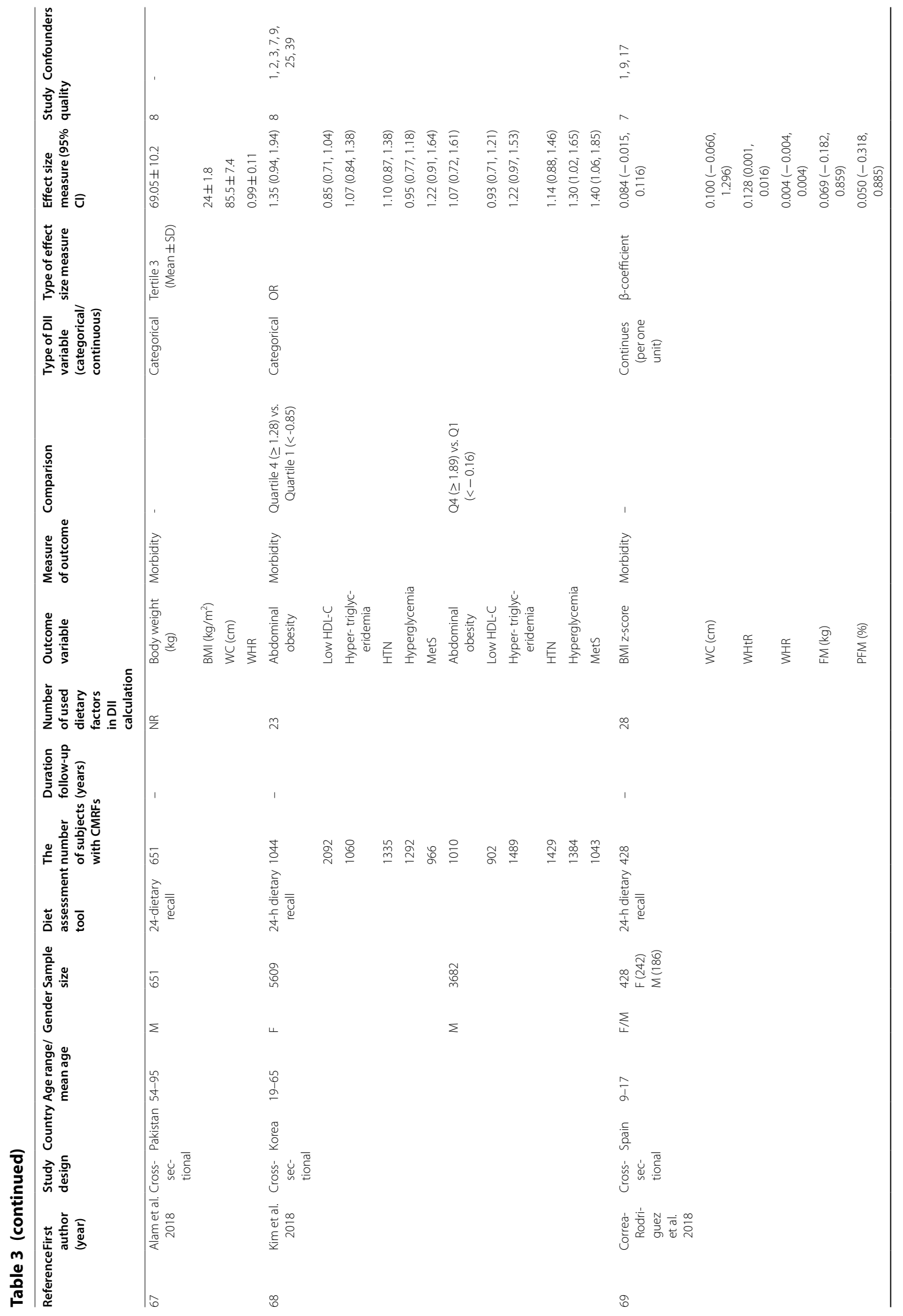




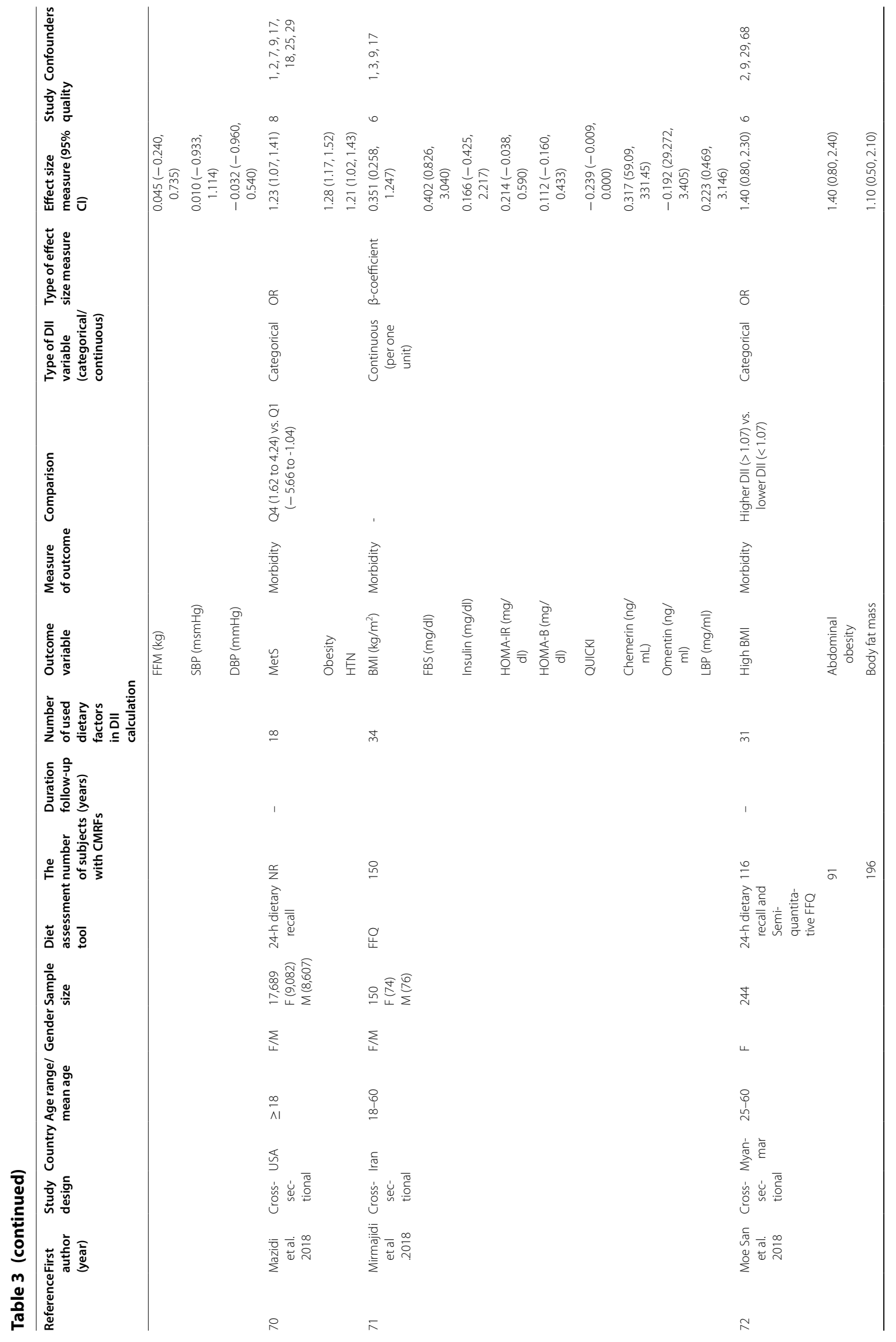




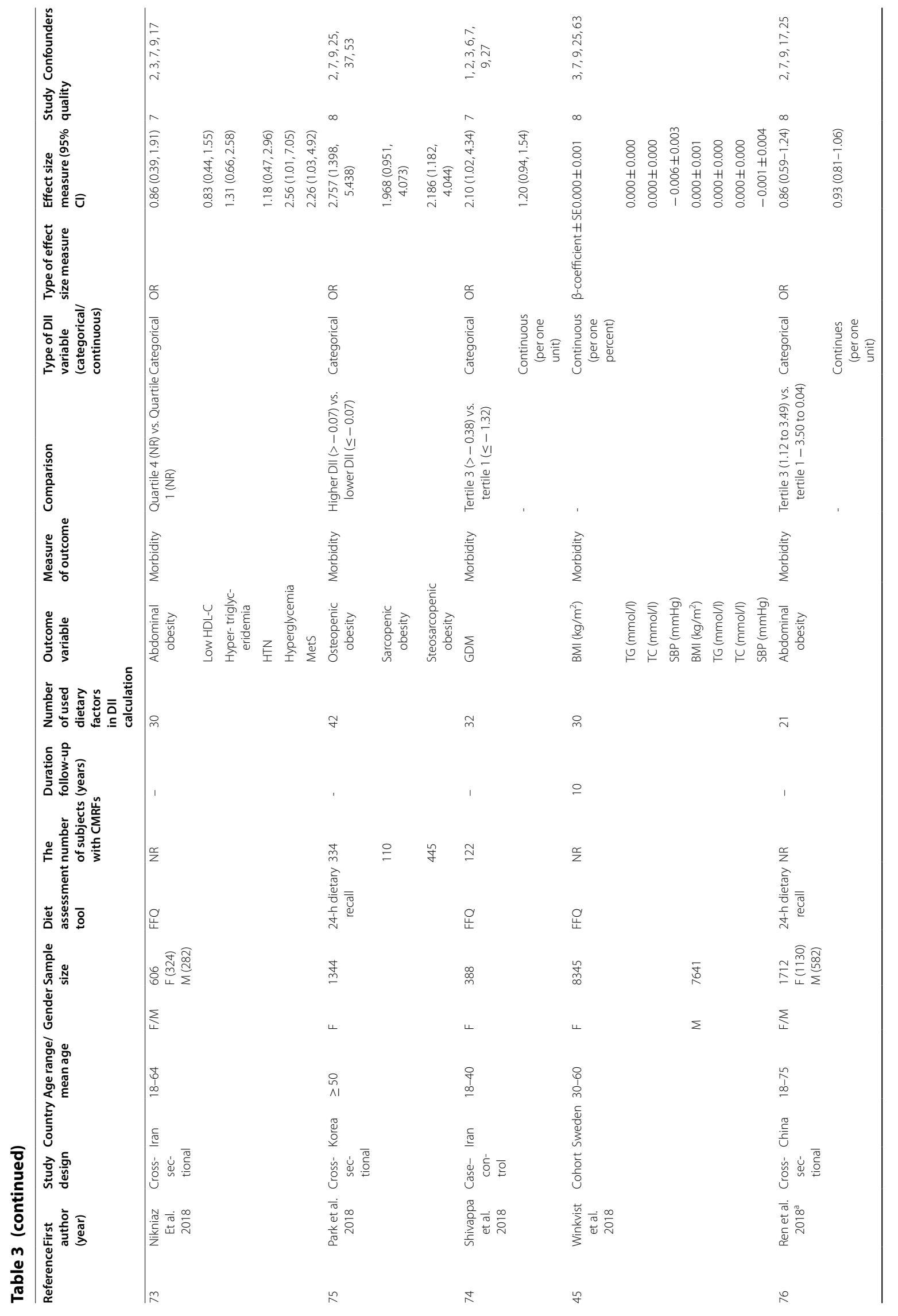




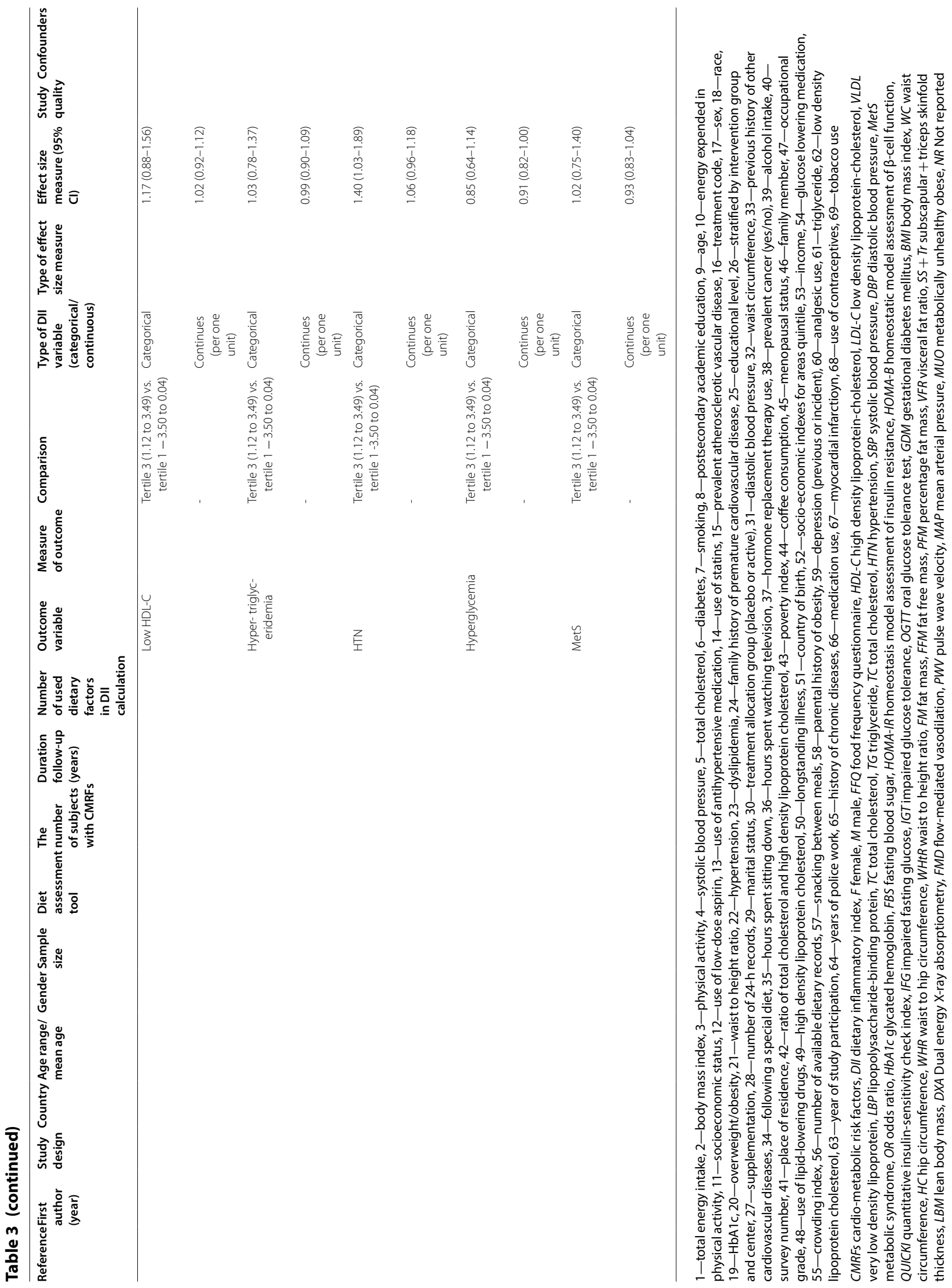




ID
Cohort studies
Garcia-Arellano, 2015
Neufcourt, 2016
Shivappa, 2017
Vissers, 2016
Shivappa, 2017
Subtotal $(\mathrm{I}-\mathrm{squared}=22.3 \%, \mathrm{p}=0.272)$

Fig. 2 Association of dietary inflammatory index (DII) (as a continuous variable) and risk of cardiometabolic diseases

DII score and BMI $[42,45,63,66]$, whereas two studies indicated a significant association $[49,71]$. Another report found a significant association between the DII score and BMI only in women [47]. One cohort study showed a significant association between the DII score and BMI z-score in boys [44]; another study failed to find any association between the DII score and BMI z-score [69]. Moreover, another study indicated this association in all students [60]. A significant association between the DII score and low density lipoprotein cholesterol (LDL-C) levels was observed in two studies $[21,65]$ and three studies failed to find any association $[42,44,48]$. The DII score was associated with total cholesterol (TC) levels only in one study [65], whereas three studies did not show this association $[42,45,48]$; another study reported no association between the DII score and hypercholesterolemia [17].

\section{Quality assessment}

According to NOS, 49 studies had high quality (NOS $\geq 7$ ) [15-17, 21-32, 42-64, 67-70, 73-79], and four studies obtained 6 stars $[65,66,71,72]$. Only, two reports achieved NOS $=5[19,20]$.

\section{Results of meta-analysis \\ DII score and risk of CMDs and mortality}

Thirteen studies that investigated the association between the DII score (as a continuous variable) and risk of CMDs and mortality were included in this meta-analysis [16, 19, 29-32, 52, 54-57, 78, 79] (Figs. 2 and 3). Subgroup analysis was performed according to the type of outcome (morbidity/mortality) and study design (cohort/ non-cohort) (Table 4). Results of fixed effect meta-analysis showed that per one-unit increment in the DII score the risk of CMDs mortality increased significantly by $4 \%$ $(\mathrm{HR}=1.04 ; 95 \% \mathrm{CI} 1.03,1.05)$. Also, a significant association was observed between the continuous DII and risk of CMDs in cohort $(\mathrm{HR}=1.06 ; 95 \% \mathrm{CI} 1.03,1.09)$ and non-cohort studies ( $\mathrm{HR}=1.06$; 95\% CI 1.03, 1.10).

We also assessed the association between the categorical DII score and risk of CMDs and mortality using 18 observational studies [15-17, 19, 29-32, 51-57, 77-79]. Meta-analysis of cohort studies showed that the most pro-inflammatory diet category (the highest DII score group) compared to the most anti-inflammatory diet category (the lowest DII score group), increases the risk of CMDs mortality by $29 \%(\mathrm{HR}=1.29 ; 95 \%$ CI $1.18,1.41)$ (Fig. 4). 
ES $(95 \% \mathrm{CI})$

Weight

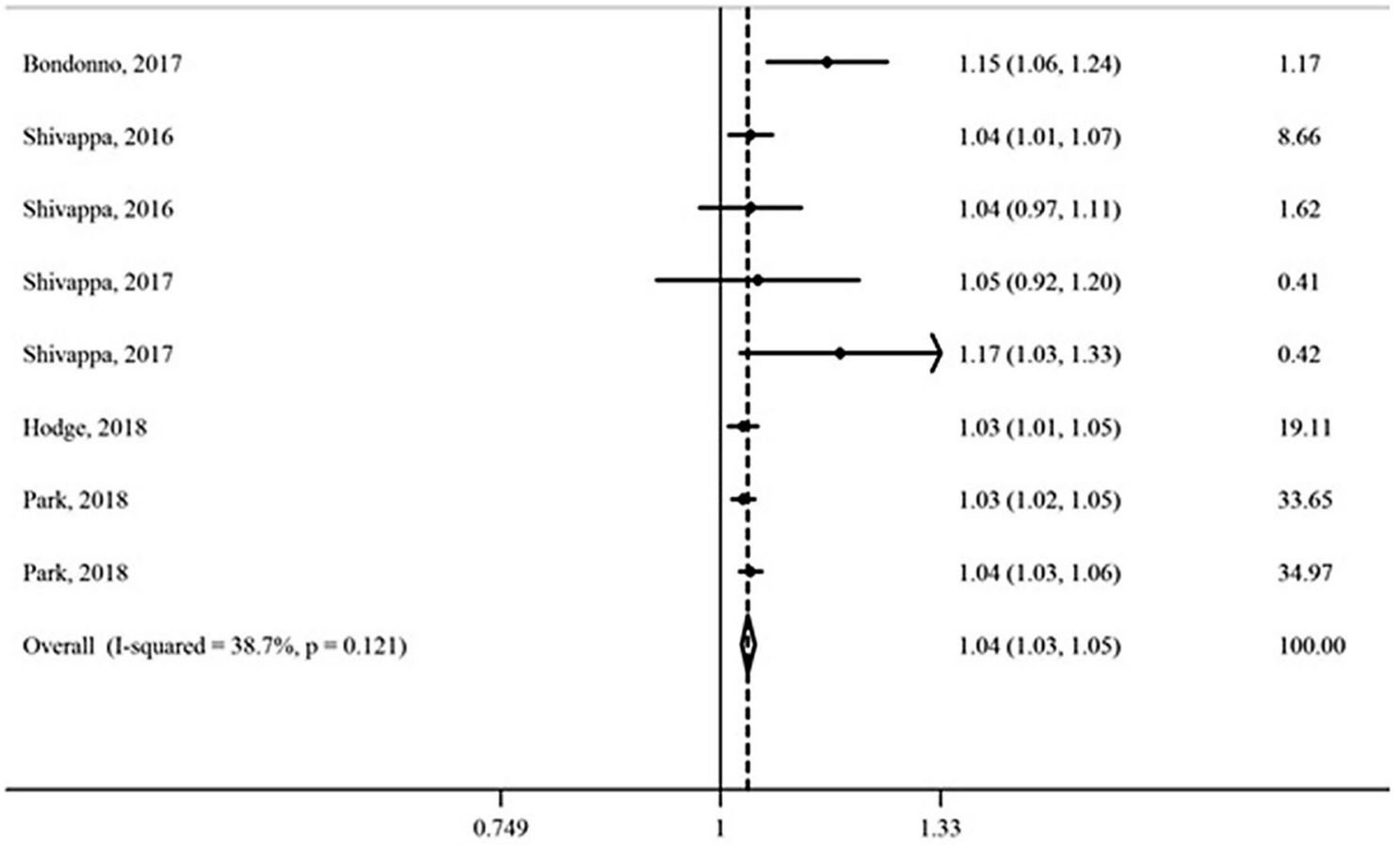

Fig. 3 Association of dietary inflammatory index (DII) (as a continuous variable) and risk of cardiometabolic diseases mortality

Also, the association between the DII and risk of CMDs was statistically significant in cohort $(\mathrm{HR}=1.35 ; 95 \% \mathrm{CI}$ $1.13,1.61)$ and non-cohort studies $(\mathrm{HR}=1.36 ; 95 \% \mathrm{CI}$ 1.18, 1.57) (Fig. 5).

\section{DII score and CMRFs}

Of 39 publications, 16 studies had assessed the association between the DII score and MetS or at least one of its components and had reported measure of association (OR) included in the meta-analysis $[17,19,20,23-26,28$, $58,61,62,68,70,72,73,76]$ (Table 5). Results of metaanalysis indicated a significant association between the DII score and MetS (OR: 1.13; 95\% CI 1.03-1.25) (Fig. 6), hyperglycemia (OR: 1.21 ; 95\% CI 1.01-1.44) and HTN (OR: 1.17 ; 95\% CI 1.10-1.25). We failed to find any significant association between the DII score and other components of MetS (abdominal obesity, low HDL-C and hyper-triglyceridemia).

\section{Results of dose-response meta-analysis}

In the terms of risk of CMDs mortality in relation to the DII score, nine cohort studies [29, 31, 51, 54-56, 77-79] were included in dose-response analysis. A significant non-linear positive association was found between the DII score and CMDs mortality $\left(\mathrm{P}_{\text {nonlinearity }}<0.001\right)$.
Unlike the overall association, the DII score was inversely associated with CMDs mortality from score of -5 to -2 $\left(P_{\text {nonlinearity }}=0.01\right)$. However, the risk was significantly increased when increasing the score of DII from -2 to $1.5\left(\mathrm{P}_{\text {nonlinearity }}<0.001\right)$. The slope was slightly flattening from DII score of 1.5 to upper levels (Additional file 3: Figure S1).

Six studies (four cohorts [16, 17, 31, 52], one casecontrol [57] and one cross-sectional study [19]) were included in dose-response analysis assessing the association between the DII score and risk of CMDs (Additional file 4: Figure S2). No significant non-linear association was found in this regard ( $\mathrm{p}$-value $=0.1$ ). Such non-significant association was also seen after considering only cohort studies and excluding case-control and cross-sectional studies ( $\mathrm{p}$-value $=0.2$ ) (Additional file 5: Figure S3).

\section{Publication bias}

No publication bias was observed between studies of MetS according to Egger test results ( $\mathrm{p}$-value $=0.323$ ). Moreover, the results of Egger test for studies evaluated the association between the continuous DII score and risk of CMDs and mortality showed that there was no evidence of publication bias between studies $\quad(p$-value $=0.114, \quad p$-value $=0.745, \quad$ respectively $)$ 


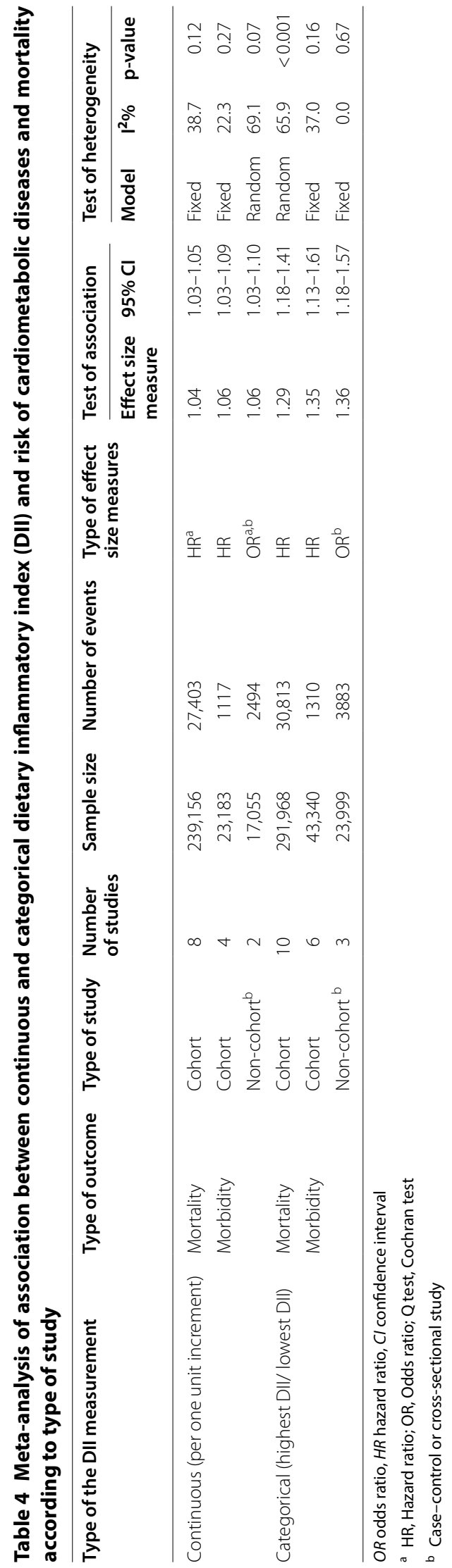




\begin{tabular}{|c|c|c|}
\hline ID & $\mathrm{ES}(95 \% \mathrm{CI})$ & Weight \\
\hline Shivappa, 2017 & $1.46(1.18,1.81)$ & 8.50 \\
\hline Shivappa, 2016 & $1.26(0.93,1.70)$ & 5.71 \\
\hline Deng, 2017 & $0.98(0.57,1.68)$ & 2.34 \\
\hline Shivappa, 2017 & $1.19(0.76,1.86)$ & 3.18 \\
\hline Deng, 2017 & $1.44(1.02,2.04)$ & 4.71 \\
\hline Bondonno,2017 & $2.02(1.30,3.13)$ & 3.28 \\
\hline Shivappa, 2016 & $1.09(1.01,1.18)$ & 14.91 \\
\hline Deng, 2017 & $1.52(1.18,1.96)$ & 7.07 \\
\hline Shivappa,2017 & $1.46(1.00,2.13)$ & 4.14 \\
\hline Hodge, 2018 & $1.17(1.07,1.27)$ & 14.55 \\
\hline Mark Park, 2018 & $\rightarrow 2.50(1.60,3.91)$ & 3.19 \\
\hline Park, 2018 & $1.13(1.03,1.23)$ & 14.41 \\
\hline Park, 2018 & $1.29(1.17,1.42)$ & 14.02 \\
\hline Overall $(\mathrm{I}$-squared $=65.9 \%, \mathrm{p}=0.000)$ & $1.29(1.18,1.41)$ & 100.00 \\
\hline NOTE: Weights are from random effects analynis & & \\
\hline 0.256 & 3.91 & \\
\hline
\end{tabular}

Fig. 4 Association of dietary inflammatory index (DII) (as a categorical variable) with risk of cardiometabolic diseases mortality

(Additional file 6: Figures S4 and Additional file 7: Figure S5). When we considered studies with the categorical DII score, the publication bias was observed in our analysis $\left(\mathrm{P}_{\text {Egger }}=0.001\right.$ for risk of CMDs and $\mathrm{P}_{\text {Egger }}=0.04$ for risk of CMDs mortaliy) (Additional file 8: Figure S6 and Additional file 9: Figure S7).

\section{Sensitivity analysis}

Sensitivity analysis showed that removing any of the studies or a group of studies could not significantly change the effect of DII score (as a continuous or categorical variable) on risk of CMDs and mortality. In terms of MetS and its components, the results of sensitivity analysis demonstrated that neither an individual study nor group of studies had a remarkable effect on our results.

\section{Discussion}

The present meta-analysis showed evidences of the association between increasing the inflammatory potential of diet and risk of CMDs and mortality. Also, individuals with the highest pro-inflammatory diet had $13 \%, 21 \%$, and $17 \%$ higher risk for MetS, hyperglycemia and HTN than those with the lowest pro-inflammatory diet.
Subgroup analysis showed that the association of DII (as continuous and categorical variable) with risk of CMDs did not change appreciably in the cohort and non-cohort studies. One important issue in studies on the association of the dietary indices and chronic diseases is the sample size. We can find more precise results using larger sample sizes. Similar findings in the cohort and non-cohort studies can be probably explained by the larger sample size of non-cohort studies.

In the current study, there was a significant association between the DII score and risk of CMDs and mortality. There are some theories that explain the relationship between the DII score and risk of CVDs. Findings of studies showed that higher consumption of pro-inflammatory foods such as red and processed meat, sugar, and refined grains increases level of IL-6, TNF-a, and hs-CRP [12]. Higher levels of these inflammatory biomarkers is the main etiologic factor in CMDs development [80-84]. Since the DII score was calculated using dietary factors (nutrients and specific food items) which show the diet-associated inflammation [14], it was anticipated to observe an association between the DII score and risk of CMDs. 


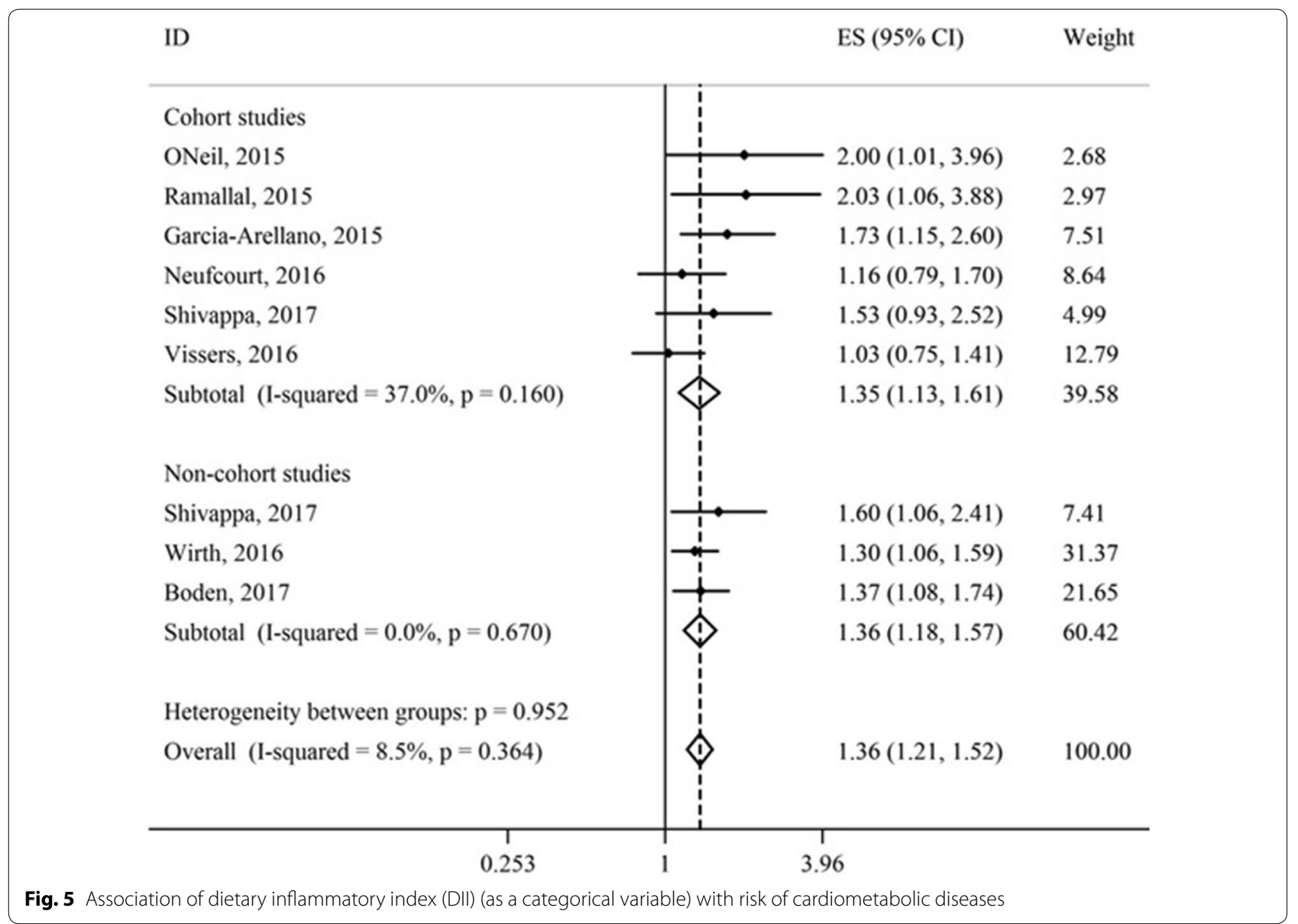

Table 5 Meta-analysis of association between dietary inflammatory index (DII) (as a categorical index) and cardiometabolic risk factors

\begin{tabular}{|c|c|c|c|c|c|c|c|c|}
\hline \multirow[t]{2}{*}{ Outcome variable } & \multirow{2}{*}{$\begin{array}{l}\text { Number } \\
\text { of studies }\end{array}$} & \multirow[t]{2}{*}{ Sample size } & \multirow[t]{2}{*}{ Number of events } & \multicolumn{2}{|c|}{ Test of association } & \multicolumn{3}{|c|}{ Test of heterogeneity } \\
\hline & & & & $\mathrm{OR}^{\mathrm{a}, \mathrm{d}}$ & $95 \% \mathrm{Cl}$ & Model & $I^{2} \%$ & p-value \\
\hline Abdominal obesity & 9 & 18,121 & $4655^{b}$ & 1.00 & $0.88-1.12$ & Fixed & 3.5 & 0.40 \\
\hline Low HDL-C & 8 & 17,874 & $4148^{b}$ & 0.94 & $0.78-1.14$ & Random & 58.1 & 0.01 \\
\hline Hyper- triglyceridemia & 8 & 17,874 & $3954^{b}$ & 1.09 & $0.98-1.22$ & Fixed & 0.0 & 0.73 \\
\hline HTN & 12 & 77,194 & $13,496^{c}$ & 1.17 & $1.10-1.25$ & Fixed & 36.4 & 0.12 \\
\hline Hyperglycemia & 8 & 17,876 & $4651^{b}$ & 1.21 & $1.01-1.44$ & Random & 54.0 & 0.02 \\
\hline MetS & 11 & 42,978 & $4524^{b}$ & 1.13 & $1.03-1.25$ & Random & 54.8 & 0.02 \\
\hline
\end{tabular}

HDL-C high density lipoprotein-cholesterol, HTN hypertension, MetS metabolic syndrome, OR odds ratio, Cl confidence interval

* HR, Hazard ratio; OR, Odds ratio; $Q$ test, Cochran test

a Cohort or cross-sectional study

b Participants with abdominal obesity, low-HDL-C, hyper-triglyceridemia, hyperglycemia and MetS had not been stated in three studies

c Participants with HTN had not been stated in five studies

d The odds ratio is for the highest pro-inflammatory diet (the highest DII) versus the highest anti-inflammatory diet (the lowest DII)

e Case-control or cross-sectional study 


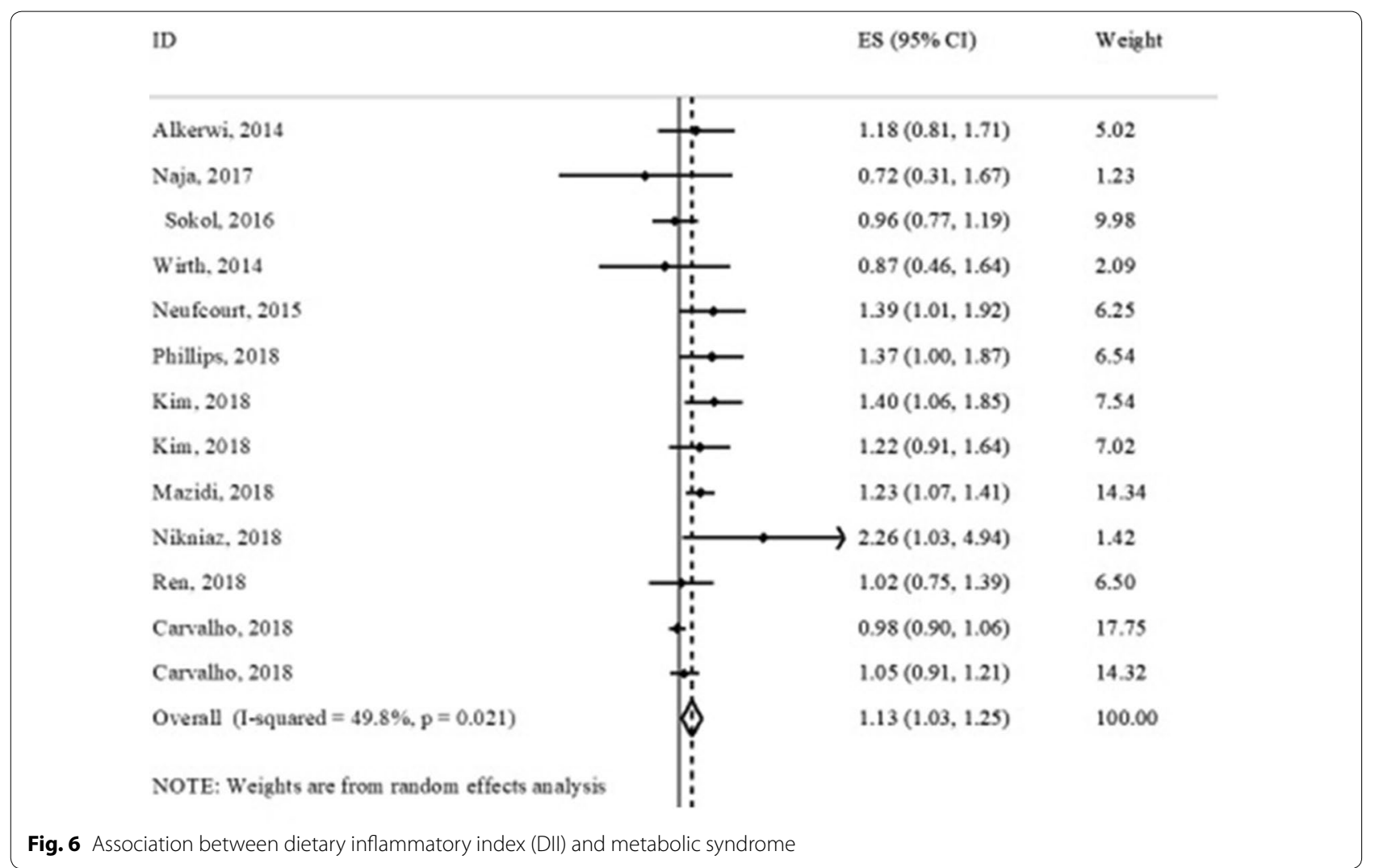

A population-based study including 1,363 men aged 18 years and older (the Geelong osteoporosis study) showed that the adjusted OR (95\% CI) for CVDs was 2 (1.01-3.96) for those with pro-inflammatory diet compared with anti-inflammatory diet [53]. The PREDIMED study investigated 7,216 men aged 55-80 years and women aged $60-80$ years at high risk of CVDs. A total of 277 CVDs events were considered. The adjusted hazard ratio (95\% CI) for CVDs was 1.73 (1.15-2.60) for participants with pro-inflammatory diet. A stronger relationship was showed when cases occurring during the first year of follow-up were excluded from the analysis [16]. Moreover, the in SU.VI.MAX study included 7743 women aged $35-60$ years and men aged $45-60$ years with 11.4 years follow-up, no statistically significant association was found between the DII score and the composite CVDs outcome. However, a significant relationship was shown for MI when the highest quartile was compared with the lowest quartile of the DII score [52]. Moreover, another cross-sectional study carried out on Sweden men and women aged 30-73 years showed a positive association between the DII score and risk of CMDs [15]. A cohort study on a large sample size of Sweden women indicated that there is not association between the DII score and risk of CVDs mortality [55]. This finding may related to the low number of used dietary factors in DII calculation. In another cohort study on diabetic patients, results showed that there is not any association between the DII score and risk of CVDs mortality that it is not in line our study. This finding can be related to the low sample size and dietary factors used for DII calculation [51].

This meta-analysis of 16 studies examining the association between the DII score and MetS or at least one of its components $[17,19,20,23-26,28,58,61$, $62,68,70,72,73,76]$, showed a significant association between the DII score and MetS, hyperglycemia and HTN. Several population-based studies carried out in France, Ireland, USA and Iran demonstrated the significant association between the DII score and MetS [23, $62,70,73]$. However, other studies failed to find this association [20, 25, 26, 28, 61, 76]. Ramallal et al. [17] in a cohort study on 18,794 Spanish men and women showed the higher DII score is associated with greater incidence of HTN. Also, other studies indicated this significant association [19, 24, 70, 76]. In the regard of hyperglycemia, studies carried out in USA and Iran indicated a positive association between the DII score and hyperglycemia [20,73]. However, some studies did not demonstrate this association $[25,26,28,58]$.

The meta-analysis of 14 studies revealed that subjects in the highest versus the lowest DII score category showed 36\% increased risk of CVDs incidence and 
mortality [33]. Another meta-analysis found that participants with higher DII score had a higher risk of cardiovascular and cancer mortality [30]. The strengths of our study against the other two meta-analyses include the evaluation of the association between the DII score and CMRFs and the dose-response association between the DII score and risk of CMDs and mortality. In addition, we assessed the risk of CMDs separately in all cohort and non-cohort studies.

The current study had several limitations. Absence of a specific cut-off point for the association of the DII score and occurrence of morbidity or mortality of CMDs is the first limitation. Most of studies included in the MetS and its components analyses had a cross-sectional design, so the limitations of this type of study should be considered and the results should be interpreted with cautious. Other limitations include different numbers of dietary factors used in the DII score calculation and applying different adjustment models in the analyses. Evidence of publication bias, the other limitation, was observed when the DII score was considered as a categorical variable in the analyses.

\section{Conclusion}

The current meta-analysis study showed a positive association between the DII score and risk of CMDs and mortality. Also, we find a significant association between adherence to pro-inflammatory diet and MetS, hyperglycemia, and HTN. More studies with prospective designs and in different societies are needed to confirm the findings.

\section{Supplementary information}

Supplementary information accompanies this paper at https://doi. org/10.1186/s13098-020-00592-6.

Additional file 1: Appendix S1. PRISMA 2009 Checklist.
Additional file 2: Table S1. Search strategy in PubMed.

Additional file 3: Figure S1. Dose-response association between the DII and risk of cardiometabolic diseases mortality.

Additional file 4: Figure S2. Dose-response association between the DII and risk of cardiometabolic diseases.

Additional file 5: Figure S3. Dose-response association between the DII and risk of cardiometabolic diseases in cohort studies.

Additional file 6: Figure S4. Funnel plot of dietary inflammatory index (DII) (as a continuous variable) with risk of cardiometabolic diseases.

Additional file 7: Figure S5. Funnel plot of dietary inflammatory index (DII) (as a continuous variable) with risk of cardiometabolic diseases mortality.

Additional file 8: Figure S6. Funnel plot of dietary inflammatory index (DII) (as a categorical variable) with risk of cardiometabolic diseases.

Additional file 9: Figure S7. Funnel plot of dietary inflammatory index (DII) (as a categorical variable) with risk of cardiometabolic diseases mortality.
Acknowledgements

Not applicable.

\section{Disclosure}

Dr. James R. Hébert owns controlling interest in Connecting Health Innovations LLC $(\mathrm{CHI})$, a company planning to license the right to his invention of the dietary inflammatory index (DII) from the University of South Carolina in order to develop computer and smart phone applications for patient counselling and dietary intervention in clinical settings. Dr. Nitin Shivappa is an employee of $\mathrm{CHI}$.

\section{Authors' contributions}

The contribution of authors was as follows- ZA: conducted systematic search on electronic databases, screened the papers, extracted the data and wrote the manuscript; OS: analyzed the data and wrote the manuscript; $\mathrm{MH}-\mathrm{B}$ : wrote the manuscript; $\mathrm{HZ}$ : wrote the manuscript, FB: wrote the manuscript; NS: wrote the manuscript; JRH: wrote the manuscript; SM: analyzed the data; GS: wrote the manuscript; HA: conducted systematic search on electronic databases, and screened the papers; SD: extracted the data; MQ: designed the study, analyzed the data and is the responsible for the final content. All authors read and approved the final manuscript.

\section{Funding}

This study was supported by National Institute for Medical Research Development (NIMAD), Grant No. 971036.

\section{Availability of data and materials}

All data generated or analyzed in this study are included in this published article [and its additional information files].

Ethics approval and consent to participate

Not applicable.

\section{Consent for publication}

Not applicable.

\section{Competing interests}

The authors declare that they have no competing interests.

\section{Author details}

${ }^{1}$ Department of Community Nutrition, School of Nutritional Sciences and Dietetics, Tehran University of Medical Sciences, Tehran, Iran. ${ }^{2}$ Students'Scientific Research Center, Tehran University of Medical Sciences, Tehran, Iran. ${ }^{3}$ Child Growth and Development Research Center, Research Institute for Primordial Prevention of Non-Communicable Disease, Isfahan University of Medical Sciences, Isfahan, Iran. ${ }^{4}$ Hematopoietic Stem Cell Research Center, Shahid Beheshti University of Medical Sciences, Tehran, Iran. ${ }^{5}$ Center of Maritime Health and Society, Department of Public Health, University of Southern Denmark, Esbjerg, Denmark. ${ }^{6}$ Cancer Prevention and Control Program, University of South Carolina, Columbia, SC 29208, USA. ${ }^{7}$ Department of Epidemiology and Biostatistics, Arnold School of Public Health, University of South Carolina, Columbia, SC 29208, USA.

${ }^{8}$ Connecting Health Innovations LLC, Columbia, SC 29201, USA. ${ }^{9}$ Halal Research Center of IRI, FDA, Tehran, Iran. ${ }^{10}$ Department of Clinical Nutrition, School of Nutrition and Food Science, Isfahan University of Medical Sciences, Isfahan, Iran. ${ }^{11}$ Department of Medical Emergencies, Qom University of Medical Sciences, Qom, Iran. ${ }^{12}$ Development of Research \& Technology Center, Ministry of Health and Medical Education, Tehran, Iran. ${ }^{13}$ Non-Communicable Diseases Research Center, Endocrinology and Metabolism Population Sciences Institute, Tehran University of Medical Sciences, Tehran, Iran. ${ }^{14}$ Non-Communicable Diseases Research Center, Alborz University of Medical Sciences, Karaj, Iran. ${ }^{15}$ Chronic Diseases Research Center, Endocrinology and Metabolism Population Sciences Institute, Tehran University of Medical Sciences, Tehran, Iran.

Received: 28 April 2020 Accepted: 22 September 2020 Published online: 07 October 2020

\footnotetext{
References

1. Libby P. Inflammatory mechanisms: the molecular basis of inflammation and disease. Nut Rev. 2007;65:S140-S146146.
} 
2. Hansson GK. Inflammation, atherosclerosis, and coronary artery disease. N Engl J Med. 2005;352:1685-95.

3. Galassetti P. Inflammation and oxidative stress in obesity, metabolic syndrome, and diabetes. J Diabetes Res. 2012;2012:943706.

4. Keibel A, Singh V, Sharma MC. Inflammation, microenvironment, and the immune system in cancer progression. Curr Pharm Des. 2009;15:1949-55.

5. Gregor MF, Hotamisligil GS. Inflammatory mechanisms in obesity. Annu Rev Immunol. 2011;29:415-45.

6. Musani SK, Vasan RS, Bidulescu A, Liu J, Xanthakis V, Sims M, et al. Aldosterone, C-reactive protein, and plasma B-type natriuretic peptide are associated with the development of metabolic syndrome and longitudinal changes in metabolic syndrome components: findings from the Jackson Heart Study. Diabetes Care. 2013:36:3084-92.

7. Esmaillzadeh A, Kimiagar M, Mehrabi Y, Azadbakht L, Hu FB, Willett WC. Dietary patterns and markers of systemic inflammation among Iranian women. J Nutr. 2007:137:992-8.

8. Fung TT, Rexrode KM, Mantzoros CS, Manson JE, Willett WC, Hu FB. Mediterranean diet and incidence of and mortality from coronary heart disease and stroke in women. Circulation. 2009;1 19:1093-100.

9. Martínez-González MA, García-López M, Bes-Rastrollo M, Toledo E, Martínez-Lapiscina EH, Delgado-Rodriguez M, et al. Mediterranean diet and the incidence of cardiovascular disease: a Spanish cohort. Nutr Metab Cardiovasc Dis. 2011;21:237-44.

10. Trichopoulou A, Martínez-González MA, Tong TY, Forouhi NG, Khandelwal S, Prabhakaran D, et al. Definitions and potential health benefits of the Mediterranean diet: views from experts around the world. BMC Med. 2014;12:112.

11. Martinez-Gonzalez MA, Bes-Rastrollo M. Dietary patterns, Mediterranean diet, and cardiovascular disease. Curr Opin Lipidol. 2014:25:20-6.

12. Lopez-Garcia E, Schulze MB, Fung TT, Meigs JB, Rifai N, Manson JE, et al. Major dietary patterns are related to plasma concentrations of markers of inflammation and endothelial dysfunction. Am J Clin Nutr. 2004:80:1029-35.

13. Cavicchia PP, Steck SE, Hurley TG, Hussey JR, Ma Y, Ockene IS, et al. A new dietary inflammatory index predicts interval changes in serum highsensitivity C-reactive protein. J Nutr. 2009;139:2365-72.

14. Shivappa N, Steck SE, Hurley TG, Hussey JR, Hébert JR. Designing and developing a literature-derived, population-based dietary inflammatory index. Public Health Nutr. 2014;17:1689-96.

15. Bodén S, Wennberg M, Van Guelpen B, Johansson I, Lindahl B, Andersson $J$, et al. Dietary inflammatory index and risk of first myocardial infarction; a prospective population-based study. Nutr J. 2017;16:21.

16. Garcia-Arellano A, Ramallal R, Ruiz-Canela M, Salas-Salvadó J, Corella D, Shivappa $\mathrm{N}$, et al. Dietary inflammatory index and incidence of cardiovascular disease in the PREDIMED study. Nutrients. 2015;7:4124-38.

17. Ramallal R, Toledo E, Martínez-González MA, Hernández-Hernández A, García-Arellano A, Shivappa N, et al. Dietary inflammatory index and incidence of cardiovascular disease in the SUN cohort. PLOS ONE. 2015:10:e0135221.

18. Li D, Hao X, Li J, Wu Z, Chen S, Lin J, et al. Dose-response relation between dietary inflammatory index and human cancer risk: evidence from 44 epidemiologic studies involving 1,082,092 participants. Am J Clin Nutr. 2018:107:371-88

19. Wirth MD, Shivappa N, Hurley TG, Hébert JR. Association between previously diagnosed circulatory conditions and a dietary inflammatory index. Nutr Res. 2016;36:227-33

20. Wirth M, Burch J, Shivappa N, Violanti JM, Burchfiel CM, Fekedulegn D, et al. Association of a dietary inflammatory index with inflammatory indices and the metabolic syndrome among police officers. J Occup Environ Med. 2014:56:986

21. Vahid F, Shivappa N, Karamati M, Naeini AJ, Hebert JR, Davoodi SH. Association between Dietary Inflammatory Index (DII) and risk of prediabetes: a case-control study. Appl Physiol Nutr Metab. 2016;42:399-404.

22. Ramallal R, Toledo E, Martínez JA, Shivappa N, Hébert JR, MartínezGonzález MA, et al. Inflammatory potential of diet, weight gain, and incidence of overweight/obesity: the SUN cohort. Obesity. 2017:25:997-1005.

23. Neufcourt L, Assmann K, Fezeu L, Touvier M, Graffouillère L, Shivappa N, et al. Prospective association between the dietary inflammatory index and metabolic syndrome: findings from the SU. VI. MAX study. Nutr Metab Cardiovasc Dis. 2015;25:988-96

24. Alkerwi AA, Shivappa N, Crichton G, Hébert JR. No significant independent relationships with cardiometabolic biomarkers were detected in the Observation of Cardiovascular Risk Factors in Luxembourg study population. Nutr Res. 2014;34:1058-65.

25. Naja F, Shivappa N, Nasreddine L, Kharroubi S, Itani L, Hwalla N, et al. Role of inflammation in the association between the western dietary pattern and metabolic syndrome among Lebanese adults. Int J Food Sci Nutr. 2017:68:997-1004.

26. Vissers L, Waller M, van der Schouw Y, Hébert J, Shivappa N, Schoenaker $\mathrm{D}$, et al. A pro-inflammatory diet is associated with increased risk of developing hypertension among middle-aged women. Nutr Metab Cardiovasc Dis. 2017:27:564-70.

27. Sen S, Rifas-Shiman SL, Shivappa N, Wirth MD, Hébert JR, Gold DR, et al. Dietary inflammatory potential during pregnancy is associated with lower fetal growth and breastfeeding failure: results from project Viva-3. Nutr. 2015:146:728-36.

28. Sokol A, Wirth MD, Manczuk M, Shivappa N, Zatonska K, Hurley TG, et al. Association between the dietary inflammatory index, waist-to-hip ratio and metabolic syndrome. Nutr Res. 2016;36:1298-303.

29. Bondonno NP, Lewis JR, Blekkenhorst LC, Shivappa N, Woodman RJ, Bondonno CP, et al. Dietary inflammatory index in relation to sub-clinical atherosclerosis and atherosclerotic vascular disease mortality in older women. Br J Nutr. 2017:117:1577-86.

30. Vissers LE, Waller MA, van der Schouw YT, Hebert JR, Shivappa N, Schoenaker DA, et al. The relationship between the dietary inflammatory index and risk of total cardiovascular disease, ischemic heart disease and cerebrovascular disease: Findings from an Australian population-based prospective cohort study of women. Atherosclerosis. 2016;253:164-70.

31. Shivappa N, Hebert JR, Kivimaki M, Akbaraly T. Alternative healthy eating index 2010, dietary inflammatory index and risk of mortality: results from the whitehall II cohort study and meta-analysis of previous Dietary Inflammatory Index and mortality studies. Br J Nutr. 2017;118:210-21.

32. Shivappa N, Schneider A, Hébert JR, Koenig W, Peters A, Thorand B. Association between dietary inflammatory index, and cause-specific mortality in the MONICA/KORA Augsburg Cohort Study. Eur J Public Health. 2017:28:167-72.

33. Shivappa N, Godos J, Hébert JR, Wirth MD, Piuri G, Speciani AF, et al. Dietary inflammatory index and cardiovascular risk and mortality-a meta-analysis. Nutrients. 2018;10:200.

34. Namazi N, Larijani B, Azadbakht L. Dietary inflammatory index and its association with the risk of cardiovascular diseases, metabolic syndrome, and mortality: a systematic review and meta-analysis. Horm Metab Res. 2018:50:345-58.

35. Zhong X, Guo L, Zhang L, Li Y, He R, Cheng G. Inflammatory potential of diet and risk of cardiovascular disease or mortality: a meta-analysis. Sci Rep. 2017;7:6367.

36. Wells GA SB, O'Connell D, Peterson J, Welch V, Losos M, Tugwell P. The Newcastle-Ottawa Scale (NOS) for assessing the quality of nonrandomised studies in meta-analyses.Ottawa Hospital Research Institue; 2014. https://www.ohri.ca/programs/_linical_epidemiology/oxford.asp. Accessed June 2016.

37. Lipsey M, Wilson D. Practical meta-analysis. Thousand Oaks: Sage Publications; 2001.

38. Higgins JP, Thompson SG. Quantifying heterogeneity in a meta-analysis. Stat Med. 2002;21:1539-58.

39. Cao YXY, Lu T, Gao F, Mo Z. Metan: fixed- and random-effects meta-analysis. Stata J. 2008:8:3-28.

40. Orsini N, Bellocco R, Greenland S. Generalized least squares for trend estimation of summarized dose-response data. Stata J. 2006;6:40

41. Harre FE Jr, Lee KL, Pollock BG. Regression models in clinical studies: determining relationships between predictors and response. J Natl Cancer Inst. 1988:80:1198-202.

42. Alkerwi AA, Vernier C, Crichton GE, Sauvageot N, Shivappa N, Hébert JR. Cross-comparison of diet quality indices for predicting chronic disease risk: findings from the Observation of Cardiovascular Risk Factors in Luxembourg (ORISCAV-LUX) study. Br J Nutr. 2015;113:259-69. 
43. Moslehi N, Ehsani B, Mirmiran P, Shivappa N, Tohidi M, Hébert JR, et al. Inflammatory properties of diet and glucose-insulin homeostasis in a cohort of iranian adults. Nutrients. 2016;8:735.

44. Sen S, Rifas-Shiman S, Shivappa N, Wirth M, Hebert J, Gold D, et al. Associations of prenatal and early life dietary inflammatory potential with childhood adiposity and cardiometabolic risk in Project Viva. Pediatr Obes. 2018;13:292-300.

45. Winkvist A, Klingberg S, Nilsson LM, Wennberg M, Renström F, Hallmans $\mathrm{G}$, et al. Longitudinal 10-year changes in dietary intake and associations with cardio-metabolic risk factors in the Northern Sweden Health and Disease Study. Nutr J. 2017;16:20.

46. Tyrovolas S, Koyanagi A, Kotsakis GA, Panagiotakos D, Shivappa N, Wirth MD, et al. Dietary inflammatory potential is linked to cardiovascular disease risk burden in the US adult population. Int J Cardiol. 2017;240:409-13.

47. Ruiz-Canela M, Zazpe I, Shivappa N, Hebert JR, Sanchez-Tainta A, Corella $D$, et al. Dietary inflammatory index and anthropometric measures of obesity in a population sample at high cardiovascular risk from the PREDIMED (PREvencion con Dleta MEDiterranea) trial. Br J Nutr. 2015;113:984-95.

48. Camargo-Ramos CM, Correa-Bautista JE, Correa-Rodríguez M, RamírezVélez R. Dietary inflammatory index and cardiometabolic risk parameters in overweight and sedentary subjects. Int J Environ Res Public Health. 2017:14:1104.

49. Cantero I, Abete I, Babio N, Arós F, Corella D, Estruch R, et al. Dietary Inflammatory Index and liver status in subjects with different adiposity levels within the PREDIMED trial. Clin Nutr. 2017:37:1736-43.

50. Tabung FK, Smith-Warner SA, Chavarro JE, Fung TT, Hu FB, Willett WC, et al. An empirical dietary inflammatory pattern score enhances prediction of circulating inflammatory biomarkers in adults. J Nutr. 2017:147:1567-77.

51. Deng FE, Shivappa N, Tang Y, Mann JR, Hebert JR. Association between diet-related inflammation, all-cause, all-cancer, and cardiovascular disease mortality, with special focus on prediabetics: findings from NHANES III. Eur J Nutr. 2017:56:1085-93.

52. Neufcourt L, Assmann KE, Fezeu LK, Touvier M, Graffouillère L, Shivappa $\mathrm{N}$, et al. Prospective association between the dietary inflammatory index and cardiovascular diseases in the Supplémentation en Vitamines et Minéraux Antioxydants (SU. VI. MAX) Cohort. J Am Heart Assoc. 2016;5:e002735

53. O'Neil A, Shivappa N, Jacka FN, Kotowicz MA, Kibbey K, Hebert JR, et al. Pro-inflammatory dietary intake as a risk factor for CVD in men: a 5-year longitudinal study. Br J Nutr. 2015;114:2074-82.

54. Shivappa N, Blair CK, Prizment AE, Jacobs DR, Steck SE, Hébert JR. Association between inflammatory potential of diet and mortality in the lowa Women's Health study. Eur J Nutr. 2016:55:1491-502.

55. Shivappa N, Harris H, Wolk A, Hebert JR. Association between inflammatory potential of diet and mortality among women in the Swedish Mammography Cohort. Eur J Nutr. 2016:55:1891-900.

56. Shivappa N, Steck SE, Hussey JR, Ma Y, Hebert JR. Inflammatory potential of diet and all-cause, cardiovascular, and cancer mortality in National Health and Nutrition Examination Survey III Study. Eur J Nutr. 2017:56:683-92.

57. Shivappa N, Tavani A, Hébert JR, Rosato V, La Vecchia C. Dietary inflammatory index and acute myocardial infarction in a large Italian case-control study. Eur J Public Health. 2017;28:161-6.

58. Abdurahman AA, Azadbakhat L, Rasouli M, Chamari M, Qorbani M, Dorosty AR. Association of dietary inflammatory index with metabolic profile in metabolically healthy and unhealthy obese people. Nutr Dietetics. 2019;76:192-8.

59. Andrade PA, Hermsdorff HHM, Leite JIA, Shivappa N, Hébert JR, Henriques $\mathrm{HKF}$, et al. Baseline pro-inflammatory diet is inversely associated with change in weight and body fat 6 months following-up to bariatric surgery. Obes Surg. 2019;29:457-63.

60. Aslani Z, Qorbani M, Hébert JR, Shivappa N, Motlagh ME, Asayesh H, et al. Association of Dietary Inflammatory Index with anthropometric indices in children and adolescents: the weight disorder survey of the Childhood and Adolescence Surveillance and Prevention of Adult Non-communicable Disease (CASPIAN)-IV study. Br J Nutr. 2019;121:340-50.
61. Carvalho CA, Silva AAM, Assunção MCF, Fonseca PCA, Barbieri MA, Bettiol $\mathrm{H}$, et al. The dietary inflammatory index and insulin resistance or metabolic syndrome in young adults. Nutrition. 2019;58:187-93.

62. Phillips C, Shivappa N, Hébert J, Perry I. Dietary inflammatory index and biomarkers of lipoprotein metabolism, inflammation and glucose homeostasis in adults. Nutrients. 2018;10:1033.

63. Correa-Rodríguez M, Rueda-Medina B, González-Jiménez E, Correa-Bautista JE, Ramírez-Vélez R, Schmidt-RioValle J. Dietary inflammatory index, bone health and body composition in a population of young adults: a cross-sectional study. Int J Food Sci Nutr. 2018;69:1013-9.

64. Denova-Gutiérrez E, Muñoz-Aguirre P, Shivappa N, Hébert J, TolentinoMayo L, Batis C, et al. Dietary inflammatory index and type 2 diabetes mellitus in adults: the diabetes mellitus survey of Mexico City. Nutrients. 2018;10:385.

65. Farhangi MA, Najafi M. Dietary inflammatory index: a potent association with cardiovascular risk factors among patients candidate for coronary artery bypass grafting (CABG) surgery. Nutr J. 2018;17:20.

66. Muhammad HFL, van Baak MA, Mariman EC, Sulistyoningrum DC, Huriyat $E$, Lee $Y Y$, et al. Dietary inflammatory index score and its association with body weight, blood pressure, lipid profile, and leptin in indonesian adults. Nutrients. 2019;11:148.

67. Alam I, Shivappa N, Hebert JR, Pawelec G, Larbi A. Relationships between the inflammatory potential of the diet, aging and anthropometric measurements in a cross-sectional study in Pakistan. Nutr Healthy Aging. 2018:4:335-43.

68. Kim H-Y, Lee J, Kim J. Association between dietary inflammatory index and metabolic syndrome in the general korean population. Nutrients. 2018;10:648.

69. Correa-Rodríguez M, González-Jiménez E, Rueda-Medina B, Tovar-Gálvez MI, Ramírez-Vélez R, Correa-Bautista JE, et al. Dietary inflammatory index and cardiovascular risk factors in Spanish children and adolescents. Res Nurs Health. 2018;41:448-58.

70. Mazidi M, Shivappa N, Wirth MD, Hebert JR, Mikhailidis DP, Kengne AP, et al. Dietary inflammatory index and cardiometabolic risk in US adults. Atherosclerosis. 2018;276:23-7.

71. Mirmajidi S, Izadi A, Saghafi-Asl M, Vahid F, Karamzad N, Amiri P, et al. Inflammatory potential of diet: association with chemerin, omentin, lipopolysaccharide-binding protein, and insulin resistance in the apparently healthy obese. J Am Coll Nutr. 2019;38:302-10.

72. San KMM, Fahmida U, Wijaksono F, Lin H, Zaw KK, Htet MK. Chronic low grade inflammation measured by dietary inflammatory index and its association with obesity among school teachers in Yangon. Myanmar Asia Pac J Clin Nutr. 2018;27:92.

73. Nikniaz L, Nikniaz Z, Shivappa N, Hébert JR. The association between dietary inflammatory index and metabolic syndrome components in Iranian adults. Prim Care Diabetes. 2018;12:467-72.

74. Shivappa N, Hébert JR, Akhoundan M, Mirmiran P, Rashidkhani B. Association between inflammatory potential of diet and odds of gestational diabetes mellitus among Iranian women. J Maternal-Fetal Neonatal Med. 2019;32:3552-8.

75. Park S, Na W, Sohn C. Relationship between osteosarcopenic obesity and dietary inflammatory index in postmenopausal Korean women: 2009 to 2011 Korea National Health and Nutrition Examination Surveys. J Clin Biochem Nutr. 2018;63:211-6.

76. Ren Z, Zhao A, Wang Y, Meng L, Szeto I, Li T, et al. Association between dietary inflammatory index, C-reactive protein and metabolic syndrome: a cross-sectional study. Nutrients. 2018;10:831.

77. Hodge AM, Bassett JK, Dugué P-A, Shivappa N, Hébert JR, Milne R, et al. Dietary inflammatory index or Mediterranean diet score as risk factors for total and cardiovascular mortality. Nutr Metab Cardiovasc Dis. 2018;28:461-9.

78. Park YMM, Choi MK, Lee SS, Shivappa N, Han K, Steck SE, et al. Dietary inflammatory potential and risk of mortality in metabolically healthy and unhealthy phenotypes among overweight and obese adults. Clin Nutr. 2019;38:682-8

79. Park S-Y, Kang M, Wilkens L, Shvetsov Y, Harmon B, Shivappa N, et al. The Dietary inflammatory index and all-cause, cardiovascular disease, and cancer mortality in the multiethnic cohort study. Nutrients. 2018;10:1844.

80. Coussens LM, Werb Z. Inflammation and cancer. Nature. 2002;420:860-7.

81. Festa A, D'Agostino R, Howard G, Mykkanen L, Tracy RP, Haffner SM. Chronic subclinical inflammation as part of the insulin resistance 
syndrome the Insulin Resistance Atherosclerosis Study (IRAS). Circulation. 2000;10:42-7.

82. Ridker PM, Cushman M, Stampfer MJ, Tracy RP, Hennekens CH. Inflammation, aspirin, and the risk of cardiovascular disease in apparently healthy men. N Engl J Med. 1997;336:973-9.

83. Shacter E, Weitzman SA. Chronic inflammation and cancer. Oncology. 2002;2002(16):217-32.
84. Wang X, Bao W, Liu J, et al. (2013) Inflammatory markers and risk of type 2 diabetes a systematic review and meta-analysis. Diabetes Care. 2013;36:166-75.

\section{Publisher's Note}

Springer Nature remains neutral with regard to jurisdictional claims in published maps and institutional affiliations.
Ready to submit your research? Choose BMC and benefit from:

- fast, convenient online submission

- thorough peer review by experienced researchers in your field

- rapid publication on acceptance

- support for research data, including large and complex data types

- gold Open Access which fosters wider collaboration and increased citations

- maximum visibility for your research: over $100 \mathrm{M}$ website views per year

At BMC, research is always in progress.

Learn more biomedcentral.com/submissions 